BIANCA COELHO MOURA

DA ESTRUTURAÇÃO A (R)EVOLUÇÃO: O CONTROLE SOCIAL INDÍGENA PÓS-CRIAÇÃO DA SECRETARIA ESPECIAL DE SAÚDE INDÍGENA. 
UNIVERSIDADE DE BRASÍLIA

FACULDADE DE CIÊNCIAS DA SAÚDE

PROGRAMA DE PÓS-GRADUAÇÃO EM SAÚDE COLETIVA

\author{
BIANCA COELHO MOURA
}

DA ESTRUTURAÇÃO A (R)EVOLUÇÃO: O CONTROLE SOCIAL INDÍGENA PÓS-CRIAÇÃO DA SECRETARIA ESPECIAL DE SAÚDE INDÍGENA.

Dissertação apresentada ao Programa de Pós Graduação em Saúde Coletiva, como requisito para a obtenção do título de Mestre em Saúde Coletiva - Mestrado Profissional, na linha de pesquisa de Políticas, Planejamento, Gestão e Atenção em Saúde.

Orientadora: Maria Fátima de Sousa

Brasília, 2016 


\title{
DA ESTRUTURAÇÃO A (R)EVOLUÇÃO: O CONTROLE SOCIAL INDÍGENA PÓS-CRIAÇÃO DA SECRETARIA ESPECIAL DE SAÚDE INDÍGENA.
}

\begin{abstract}
Dissertação apresentada ao Programa de Pós Graduação em Saúde Coletiva, como requisito para a obtenção do título de Mestre em Saúde Coletiva - Mestrado Profissional, na linha de pesquisa de Políticas, Planejamento, Gestão e Atenção em Saúde.
\end{abstract}

\section{BANCA EXAMINADORA:}

Prof. Dra . Maria Fátima de Sousa Presidente

Profa. Dra. Ana Valéria Machado Mendonça Examinadora Titular do Programa

Dra. Luciana Benevides Ferreira Examinador Externo

Profa. Dr. Claudio Fortes Garcia Lorenzo

Examinador Suplente 
[...] um índio preservado em pleno corpo físico, em todo sólido, todo gás e todo líquido.

Em átomos, palavras, alma, cor.

Em gesto, em cheiro, em sombra, em luz, em som magnífico.

Num ponto equidistante entre o Atlântico e o Pacífico, do objeto-sim resplandecente descerá o índio e as coisas que eu sei que ele dirá, fará.

Não sei dizer assim de um modo explícito [...] E aquilo que nesse momento se revelará aos povos, surpreenderá a todos não por ser exótico, mas pelo fato de poder ter sempre estado oculto, quando terá sido o óbvio.

Fragmentos da música "Um Índio" de Caetano Veloso. 


\section{AGRADECIMENTOS}

À Deus pela proteção e amor recebidos durante toda a minha vida que me sustenta diariamente.

Aos meus pais, Antônia Maria Coelho Moura e Manoel João de Moura Sobrinho, pelo amor incondicional que fizeram de mim reflexo de seu caráter, honestidade e determinação.

A minha amada irmã (in memoriam) Bruna Coelho Moura, anjo da minha vida, que está sempre presente no meu dia a dia, mesmo em outro plano espiritual.

Ao mestre, amigo e conselheiro Antônio Alves de Souza, a quem dedico este trabalho, pela sua simplicidade, paciência, honestidade e sabedoria, sendo fonte inspiradora de vida e trabalho, principalmente nos desafios da gestão da saúde indígena, mostrando através de sua amizade que é possível acreditar naquilo que se sonha.

Aos meus irmãos de alma e coração, Wando Coelho, José Cândido Mesquita Paula Cristina, Luciana Barros em especial Edson Oliveira pela cumplicidade e amizade e por ter contribuindo incomensuravelmente para realização desse trabalho.

A minha querida orientadora Maria Fátima Sousa, pela paciência e sabedoria ao lidar com minhas angustias e sonhos. Seu caráter, sua força e sua determinação foram fontes inspiradoras para que a realização desse sonho se tornasse possível. A você, meu carinho e meu respeito.

Aos Professores e todo corpo técnico da Faculdade de Ciências da Saúde da Universidade de Brasília, em especial a Valéria Mendonça, pelo prazer da convivência, amizade, companheirismo e troca de experiências.

Aos Povos Indígenas do Brasil, em especial ao Fórum de Presidentes dos Conselhos Distritais de Saúde Indígena e aos conselheiros e conselheiras que exercem com maestria o controle social no Subsistema, a qual tenho aprendido cotidianamente.

Aos companheiros de luta que fiz durante essa missão na gestão da saúde indígena, Carmem Pankararu, William Xacriabá, Nelson Mutzie Alda Uchoa, Ivaneizilia Noleto, Cleidiane Carvalho, Antônio Fernando, Herodoto Jean, Adarcyline Rodrigues, Genilda Leão, Douglas Lana e em especial ao amigo Dro Daniel Ignachitti Lacerda. Minha eterna gratidão. 
À equipe da Assessoria de Apoio ao Controle Social, pelo apoio incondicional para os desenvolvimentos das atividades que me forma delegadas, Marcos Pádua, Ana Paula Milhomem, Marina Mariane, Herla Gomes, Gisely Pasquini, Thais Torres, Thais Xavier, Janini Ginani, Maurício Mandelli e Wânia Bertanha.

Aos colegas de turma, pela companhia e por todo apoio recebido, sei que nossa relação de troca de experiências muito nos ensinou.

Por fim, agradeço a todos que estiveram e continuam, aos que já andaram comigo e aos que ainda andam, sei que nem todos os tesouros desta terra se comparam a diversidade e riqueza de amigos que possuo. Muito obrigado! 


\section{RESUMO}

A presente pesquisa objetiva discutir o processo de reorganização do controle social indígena a partir da criação da Secretaria Especial de Saúde Indígena do Ministério da Saúde, em 2010, destacando as estratégias adotadas, iniciativas promovidas pela gestão, além dos principais problemas enfrentados, buscando compreender o processo pelo qual o subsistema alcançou seus resultados, positivos e negativos, analisando a dinâmica da intervenção estatal e os problemas concretos advindos da sua implementação. Trata-se de um estudo qualiquantitativo, que utilizou informações obtidas por meio de diversas fontes públicas. Foi realizada análise de documentos, relatórios e informes técnicos produzidos pela SESAI, bem como relatórios de gestão da secretaria. Utilizou-se, também, informações de indicadores demográficos e socioeconômicos do Instituto Brasileiro de Geografia e Estatística (IBGE), bem como dispositivos legais, como, leis, portarias, decretos, além de pesquisas bibliográficas que se relacionam com o tema abordado. Os resultados evidenciam o fortalecimento das instâncias de controle social, observadas pelo contexto histórico da saúde indígena e, ainda, apresentadas em três categorias construídas a partir dos dados coletados, 1 . Organização e caracterização do Controle Social; 2. Qualificação dos Conselheiros; e 3. Investimento, as quais apresentam os desafios e avanços evidenciados a partir dos achados. Conclui-se com esta pesquisa que existe uma gama de desafios a ser enfrentado pela gestão da saúde indígena no Brasil, porém a criação da Secretaria Especial de Saúde Indígena do Ministério da Saúde favoreceu de forma sistemática e estrutural o fortalecimento do controle social da saúde indígena, principalmente na regulamentação dos papeis de cada instância de controle, na capacitação e formação dos conselheiros e conselheiras da saúde indígena, no crescente investimento nos programas e ações voltados ao controle social no subsistema e, ainda, na garantia do respeito aos processos democráticos estabelecidos pela atual organização do controle social da saúde indígena, representada hierarquicamente por suas instâncias.

PALAVRAS CHAVE: Controle Social; Participação Social; Saúde Pública; Gestão em Saúde; Saúde Indígena; Secretaria Especial de Saúde Indígena; Ministério da Saúde. 


\section{ABSTRACT}

This research aims to discuss the reorganization of the indigenous social control from the creation of the Special Secretariat of Indigenous Health of the Ministry of Health in 2010, highlighting the strategies adopted, initiatives promoted by the management, in addition to the major problems faced, trying to understand the process by which the subsystem has achieved its results, positive and negative, analyzing the dynamics of state intervention and the practical problems arising from its implementation. This is a quantitative and qualitative study, using information obtained from various public sources. Document analysis was performed, reports and technical reports produced by SESA and the secretariat management reports. It was used also demographic and socioeconomic indicators to the Brazilian Institute of Geography and Statistics (IBGE), as well as legal provisions, such as laws, ordinances, decrees, and literature searches that relate to the topic discussed. The results show the strengthening of social control instances, observed by the historical context of indigenous health and also presented in three categories constructed from the data collected, 1. Organization and characterization of Social Control; 2.Qualification of Directors; and 3.investment, which present challenges and advances evidenced from the findings. The conclusion of this research that there is a range of challenges to be faced by the management of indigenous health in Brazil, but the creation of the Special Secretariat of Indigenous Health of the Ministry of Health favored systematically and structurally strengthening the social control of indigenous health mainly in the regulation of the roles of each level of control, training and training of counselors and advisors of indigenous health, increasing investment in programs and actions aimed at social control in the subsystem, and also in ensuring respect for democratic processes established by current organization of social control of indigenous health, represented hierarchically by its instances.

KEY WORD- Social Control; Social Participation; Public Health; Health Management; Indigenous Health; Special Indigenous Health; Ministry of Health. 


\section{LISTA DE ABREVIATURAS}

CNSPI - Conferência Nacional de Proteção à Saúde do Índio

CNSPI- Conferência Nacional de Saúde para os Povos Indígenas

CNSI- Conferência Nacional de Saúde Indígena

CF - Constituição Federal

CISI - Comissão Intersetorial de Saúde Indígena

CLSI - Conselho Local de Saúde Indígena

CNS - Conselho Nacional de Saúde

CONDISI - Conselho Distrital de Saúde Indígena

DSEI - Distrito Sanitário Especial Indígena

FPCONDISI- Fórum de Presidentes de Conselho Distrital de Saúde Indígena FUNASA-Fundação Nacional de Saúde

MS - Ministério da Saúde

PNASPI- Política Nacional de Atenção à Saúde dos Povos Indígenas

SASISUS - Subsistema de Atenção à Saúde Indígena do SUS

SESAI - Secretaria Especial de Saúde Indígena

SUS - Sistema Único de Saúde 


\section{LISTA DE GRÁFICOS}

Gráfico 1. Quantitativo por sexo dos segmentos que compõem o controle social 47 da saúde indígena.

Gráfico 2. Faixa etária por segmento representativo do Controle Social

Indígena.

Gráfico 3. Distribuição de conselheiros dos conselhos distritais de saúde

indígena por capacitação recebida

Gráfico 4. Escolaridade dos conselheiros por segmento representativo do 51 Controle Social na Saúde Indígena 


\section{LISTA DE FIGURA}

Figura 1. Mapa dos Distritos Sanitários Especiais Indígenas- DSEI 25

Figura 2. Organização do DSEI e Modelo Assistencial da Saúde Indígena 26

Figura 3. Fluxo de processos do Controle Social Indígena por divisão de tarefas 47 


\section{LISTA DE TABELAS}

Tabela1. Quantitativo dos conselhos nos âmbitos local, distrital e de fórum. 45

Tabela 2. Quantitativo de conselheiros por conselho e fórum no período de 46 2011 a 2015.

Tabela 3. Quantitativo de conselheiros que receberam capacitação dentro do

Subsistema de Atenção à Saúde Indígena do Sistema Único de Saúde no período de 2011 a 2015.

Tabela 4. Investimento da SESAI no Controle Social da Saúde Indígena nos 52 últimos cinco anos.

Tabela 5. Instrumentalização do Controle Social da Saúde Indígena no ano de 53 2011. 


\section{SUMÁRIO}

APRESENTAÇÃO......................................................................................... 13

INTRODUÇÃO.............................................................................................. 15

METODOLOGIA …............................................................................... 19

REFERENCIAL TEÓRICO.................................................................. 21

A Saúde Indígena no Brasil: do direito à saúde ao seu controle 21 social

As Conferências Nacionais de Saúde Indígena..................................................

RESULTADOS E DISCUSSÕES...................................................................... 34

Estruturação do Controle Social após a criação da Secretaria Especial de Saúde Indígena: mobilização, representatividade e (r)evolução “....................................... 35

CONSIDERAÇÕES FINAIS............................................................................. 56

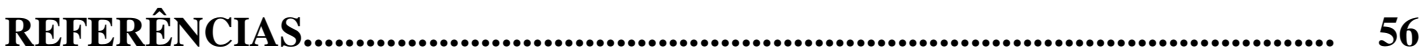

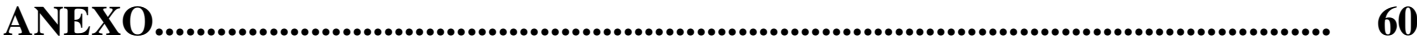




\section{APRESENTAÇÃO}

Este trabalho tem início como parte da minha experiência na Secretaria Especial de Saúde Indígena do Ministério da Saúde. Ao longo dos cinco anos a frente da assessoria de apoio ao controle social, pude acompanhar o processo de transição da gestão da saúde indígena da Fundação Nacional de Saúde (FUNASA) para Secretaria Especial de Saúde Indígena (SESAI), além do processo de reestruturação dos conselhos de saúde indígena, que permeou desde as atividades de revisão dos regimentos internos , processos eleitorais e reuniões e capacitações/ qualificação dos conselheiros locais, distritais a membros do Fórum de Presidentes de Conselhos Distritais de Saúde Indígena (FPCONDISI).

Essa experiência institucional foi um ponto de partida para despertar o interesse em pesquisar sobre o controle social na saúde indígena, em um âmbito geral, pós criação da Secretaria Especial de Saúde Indígena (SESAI).

São inúmeros os relatos de que nos últimos anos, a criação da SESAI foi uma das maiores conquistas dos povos indígenas, como também o fortalecimento do controle social, sendo este uma bandeira de luta do movimento indígena e do Fórum de Presidentes dos Conselhos Distritais de Saúde Indígena (FPCONDISI).

$\mathrm{Na}$ introdução deste trabalho são apresentados elementos que conceitua a participação popular e evidencia os entraves e conquistas que levaram ao surgimento do Controle Social na Saúde Indígena.

A metodologia reúne os percursos e recursos que chegaram aos resultados e que reforçam a justificativa para realização do estudo. 
O referencial teórico aborda os caminhos percorridos desde o reconhecimento do direito à saúde dos povos indígenas até o estabelecimento das instâncias de controle social da saúde indígena, como também os instrumentos que levaram a solidificação do controle social indígena, que também foram as conferências nacionais de saúde indígena.

Os resultados e discussões são apresentados no artigo intitulado "Estruturação do Controle Social após a criação da Secretaria Especial de Saúde Indígena: mobilização, representatividade e (r)evolução“, submetido a revista Tempus Actas de Saúde Coletiva da Universidade de Brasília. 


\section{INTRODUÇÃO}

Muito se tem pesquisado e discutido sobre a participação da sociedade nos debates e tomadas de decisões do Estado, principalmente no que concerne as formulações de políticas publicas. A intensificação do debate foi iniciada em meados da década de setenta período do surgimento de novos movimentos sociais (ROCHA, 2008).

É inquestionável que a efetiva participação social só ocorreu a partir do processo de redemocratização do Brasil e que foi legitimado e institucionalizado com a Constituição Federal de 1988, também conhecida como Constituição Cidadã (ROCHA, 2008). Nesse trabalho a ênfase sobre a participação social será dada a política pública de saúde, em especial para participação da comunidade indígena e ou povos indígenas no processo de formulação e fiscalização das ações e serviços de saúde prestados pela União.

Instituído o Sistema Único de Saúde (SUS), em 1988, do artigo 196 ao 200, mas regulamentado somente em 1990, pelas Leis Orgânicas da Saúde nº 8.080 e nº 8.142, que dispõem respectivamente sobre as condições para a promoção, proteção e recuperação da saúde, a organização e o funcionamento dos serviços para população, bem como a participação da comunidade e os transferências dos repasses financeiros para garantia da assistência à saúde . Essas leis não mencionaram as especificidades dos povos indígenas, bem como a forma de atendimento de saúde que seriam prestados aos

primeiros habitantes do país, mesmo reconhecendo na mesma Constituição Cidadã as especificidades desses povos quanto a organização social, costumes, línguas, crenças e tradições, como também os direitos originários sobre as terras que tradicionalmente 
ocupam, “competindo à União demarcá-las, proteger e fazer respeitar todos os seus bens" (BRASIL, 2000).

Somente após nove anos da criação do SUS, o Congresso Nacional aprovou a criação do Subsistema de Atenção à Saúde Indígena (SASI) como parte integrante do Sistema Único de Saúde (SUS) através da Lei no 9.836 de 23 de setembro de 1999, também conhecida como Lei Arouca. A referida lei trata da garantia e condições para a promoção de saúde e as ações de assistência relacionadas à atenção integral aos povos indígenas, levando em consideração a realidade local e as especificidades da cultura dos povos indígenas, pautado por uma abordagem diferenciada (BRASIL, 1999).

Essa mesma lei também buscou garantir a participação dos indígenas nos órgãos colegiados de formulação, o acompanhamento e avaliação das políticas públicas de saúde (BRASIL, 1999), ou seja, nas instâncias de controle social até então existentes, mas sem ainda mencionar um espaço de controle social específico para os povos indígenas.

Contudo, só na Política Nacional de Atenção à Saúde dos Povos Indígenas (PNASPI) que os conselhos de saúde indígena são mencionados, esclarecendo ainda como se daria sua forma de organização. Mas somente com publicação da Portaria GM/MS n $n^{\circ} 755 / 2012$, que foi oficialmente institucionalizado as instâncias de controle social na saúde indígena, os Conselhos Locais de Saúde Indígena (CLSI), os Conselhos Distritais de Saúde Indígena (CONDISI) e o Fórum de Presidentes de Conselhos Distritais de Saúde Indígena (FPCONDISI), (RODRIGUES, 2012).

Embora alguns pesquisadores tenham estudado o movimento de distritalização sanitária na saúde indígena (ATHIAS \& MACHADO, 2001; GARNELO \& SAMPAIO, 
2005), tema controle social ainda é pouco explorado, há poucos artigos sobre o mesmo pós-criação da SESAI, o qual podemos destacar autores como (TEIXEIRA, 2013), que traz a participação dos indígenas na Comissão Intersetorial de Saúde Indígena (CISI) do Conselho Nacional de Saúde (CNS), mas analisa ou menciona os conselhos de saúde indígena (local e distrital). Porém até o momento somente uma pesquisa buscou apresentar o controle social indígena como um todo, contudo sob o olhar da bioética, (FERREIRA, 2012), o estudo buscou analisar as tensões entre a afirmação formal, a prática do controle social e a percepção do usuário quanto à importância dos espaços formais de controle social da saúde indígena, além de analisar as especificidades na configuração do controle social do subsistema.

Contudo, a presente dissertação busca relatar o processo de (re)organização do controle social pós criação da SESAI, como forma de registrar se os avanços e limitações do fortalecimento do controle social a partir da criação da mesma.

A escassez de estudos que traçam uma análise sobre o histórico do controle social na saúde indígena, bem como os percursos que levaram à atual configuração e a carência de pesquisas institucionais e não institucionais sobre o desenvolvimento da participação social na saúde indígena têm dificultado o conhecimento da dimensão de seus resultados pós- criação da SESAI. Essas informações podem ser utilizadas para melhorar e fortalecer cada vez mais as instâncias de controle social e a participação dos povos indígenas nos espaços de tomada de decisão e proposição de estratégias que culminem numa saúde de qualidade.

Por se tratar de um tema complexo e abrangente e em função de minha atual posição profissional - membro integrante do corpo dirigente do nível central 
responsável por formulação e implementação da política de saúde indígena no país adotou-se como campo de trabalho a análise da macropolítica. Nesse contexto, esse estudo pretende refletir acerca dos registros atuais da gestão, para o fortalecimento do controle social do Subsistema de Atenção à Saúde Indígena, que é objeto dessa pesquisa.

Por isso, tona-se imperioso discutir o processo de reorganização do controle social indígena a partir da criação da SESAI, destacando as estratégias adotadas, iniciativas promovidas pela gestão, além dos principais problemas enfrentados. Além disso, é fundamental compreender o processo pelo qual o subsistema alcançou ou não seus resultados, analisando a dinâmica da intervenção estatal e os problemas concretos advindos da sua implementação. 


\section{METODOLOGIA}

Por se tratar de um tema complexo e abrangente, que por sua vez envolve inúmeros aspectos e dimensões da política setorial de saúde indígena, optou-se por um estudo qualitativo analítico e descritivo.

Para Godoy (1995), a pesquisa qualitativa tem o ambiente natural como fonte direta de dados e o pesquisador como instrumento fundamental. Os estudos denominados qualitativos têm como preocupação fundamental o estudo e a análise do mundo empírico em seu ambiente natural. Nessa abordagem valoriza-se o contato direto e prolongado do pesquisador com o ambiente e a situação que está sendo estudada, sendo que o pesquisador deve aprender a usar sua própria pessoa como o instrumento mais confiável de observação, seleção, análise e interpretação dos dados coletados.

Em função da natureza do problema que se quer estudar e das questões e objetivos que orientam a investigação, a opção pelo enfoque qualitativo muitas vezes se torna a mais apropriada. Quando o estudo é de caráter descritivo e o que se busca é o entendimento do fenômeno como um todo, na sua complexidade. Ainda quando a preocupação for a compreensão da teia de relações sociais e culturais que se estabelecem no interior das organizações. Nesse sentido, a opção pela metodologia qualitativa se faz após a definição do problema e do estabelecimento dos objetivos da pesquisa que se quer realizar (GODOY,1995).

A oportunidade de ter atuado como gestor de saúde e ter discutido e vivenciado diversas questões e situações que envolvem o controle social na saúde indígena também me ofereceu, como observador-participante, importantes elementos que contribuíram para a reflexão sobre a temática. 
É importante esclarecer que nesse estudo, embora haja uma referência sobre minha atuação profissional no campo da saúde indígena, a dimensão que se destaca é a do pesquisador, que buscar contribuir para ampliação do conhecimento nessa área.

Para o alcance dos objetivos desse trabalho foram utilizadas informações obtidas por meio de diversas fontes públicas. Foi realizada análise de documentos, relatórios e informes técnicos produzidos pela SESAI, bem como relatórios de gestão da secretaria. Utilizou-se, também, dispositivos legais, como, leis, portarias, decretos, além de pesquisas bibliográficas que se relacionam com o tema abordado.

Para coleta dos dados nos materiais pesquisados foram utilizadas três categorias pré-estabelecidas, as quais foram: Organização e Caracterização do Controle Social; Qualificação dos Conselheiros e Investimentos. Justificada pela intensa manifestação por parte dos conselheiros indígenas e do movimento indígena durante todo processo de discussão e criação da Secretaria Especial de Saúde Indígena, onde constantemente a pauta "capacitação do controle social” e "financiamento" eram levantados, a seleção das categorias em pauta está alinhada ao compromisso da gestão em iniciar o processo de reorganização e fortalecimento do controle social no Subsistema de Atenção à Saúde Indígena. Os dados referentes a amostra englobam vinte e quatro dos trinta e quatro Conselhos Distritais de Saúde Indígena. 


\section{REFERENCIAL TEÓRICO}

\section{A Saúde Indígena no Brasil: do direito à saúde ao seu controle social.}

A Constituição Federal (CF) do ano de 1988 foi um marco importante para a consolidação do regime democrático no Brasil, pois instituiu bases jurídicas para o reconhecimento dos direitos sociais do povo brasileiro, principalmente no que diz respeito à saúde, como descrito no Art. 196 da CF/88, da Seção II destinada à Saúde, do Capítulo II (da Seguridade Social):

\footnotetext{
“a saúde é direito de todos e dever do Estado, garantindo mediante políticas sociais e econômicas que visem à redução do risco de doença e de outros agravos e ao acesso universal e igualitário às ações e serviços para sua promoção, proteção e recuperação" (BRASIL, 2000).
}

Nesse sentido, o Art. 198 da CF enfatiza que

“as ações e serviços públicos de saúde integram uma rede regionalizada e hierarquizada e constituem um sistema único, organizado de acordo com as seguintes diretrizes: I - descentralização, com direção única em cada esfera de governo; II - atendimento integral, com prioridade para atividades preventivas, sem prejuízo dos serviços assistenciais; III - participação social” (BRASIL, 2000).

Contudo, o Sistema Único de Saúde (SUS) foi estabelecido pela Constituição Federal de 1988 e regulamentado pelas Leis nº 8.080/1990 e nº 8.142/1990, que compõe o atual arranjo organizacional do Estado brasileiro que dá suporte para a execução da política de saúde no país, o qual segue princípios doutrinários e organizativos, como a universalidade, a integralidade, a organização descentralizada, hierarquizada e com participação da população (BRASIL, 2011).

A Lei $n^{0}$ 8.080/90 “dispõe sobre as condições para promoção, proteção e recuperação da saúde, a organização e o funcionamento dos serviços correspondentes e 
dá outras providências" (BRASIL, 2011). Para que seja assegurada a qualidade dos serviços prestados é de suma importância que haja a participação da sociedade no processo de fiscalização da atenção à saúde. Para tanto, a Lei nº 8.142/1990, permitiu a participação da comunidade na gestão do SUS nas formas de instâncias colegiadas, como as Conferências de Saúde e os Conselhos de Saúde, que proporcionam uma forma de controle social sobre o SUS, obedecendo ao critério de composição paritária (BRASIL, 2011).

Assim, uma das características principais do SUS é a democracia, visto que assegura o direito de participação de todos os segmentos envolvidos com o sistema único - dirigentes institucionais, prestadores de serviços, trabalhadores da saúde e, principalmente, a comunidade, a população, os usuários dos serviços de saúde. Esse direito implica a participação de todos esses segmentos no processo de tomada de decisão sobre as políticas que são definidas no seu nível de atuação, assim como no controle sobre a execução das ações e serviços de saúde (BRASIL, 2011), estendendo às populações específicas, como a população indígena, que conquistaram direitos igualitários e singulares ao mesmo tempo.

Os povos indígenas reivindicaram a criação de um sistema de saúde específico e universal que lhes garanta a participação nos processos decisórios de planejamento, execução avaliação das ações e serviços de saúde. Para atender essa demanda, foi criada a Lei $\mathrm{n}^{\circ} 9.836$ de setembro de 1999 (BRASIL, 2009).

Em setembro de 1999 foi sancionada a Lei $n^{\circ}$ 9.836, amplamente conhecida como Lei Arouca (BRASIL, 2009). Essa legislação acrescenta dispositivos à Lei $n^{\circ}$ 8.080/90 ao instituir o Subsistema de Atenção à Saúde Indígena, além de integrar a Lei 
$\mathrm{n}^{\mathrm{o}} 8.142$, que posteriormente será elucidada no próximo capítulo deste documento (BRASIL, 1990; 2011).

Como o SUS, esse Subsistema deverá ser descentralizado, hierarquizado e regionalizado. Contudo, nas regiões onde residem as populações indígenas poderão ocorrer adaptações na organização e estrutura do SUS, para dessa maneira proporcionar a integração e o atendimento necessário (BRASIL, 1999; 2011).

O Subsistema de Atenção à Saúde Indígena do SUS (SAISISUS), atualmente está organizado em 34 Distritos Especiais de Saúde Indígena (DSEI) localizados em todas as regiões do território brasileiro. Essas unidades são espaços étnico-culturais dinâmicos que auxiliam na organização dos serviços de saúde e no cumprimento das diretrizes estipuladas para execução de ações de atenção à saúde, considerando as especificidades de cada povo indígena com intenção de proporcionar um atendimento de qualidade e sem discriminações (BRASIL, 2009).

A Lei Arouca enfatiza no art. 19-F a obrigatoriedade de:

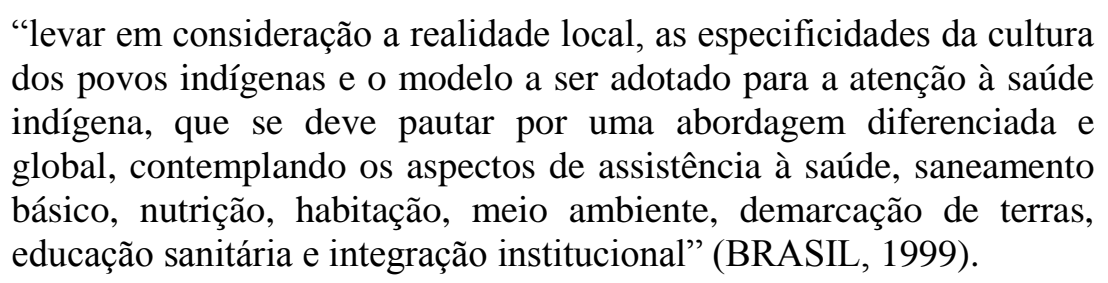

Por meio dessa lei, a população indígena deverá ter acesso garantido ao SUS e atenção de saúde em níveis primário, secundário e terciário, em âmbito local, regional e a centros especializados (BRASIL, 1999).

Assim como o SUS, o SASISUS também determina o direito da participação da população indígena nas instâncias e organismos colegiados, como descrito no art. 19-H, da Lei no 9.836/1999: “as populações indígenas terão direito a participar dos organismos colegiados de formulação, acompanhamento e avaliação das políticas de saúde, tais 
como o Conselho Nacional de Saúde e os Conselhos Estaduais e Municipais de Saúde, quando for o caso" (BRASIL, 2011).

Desse modo, é garantida a participação dos usuários indígenas no planejamento, acompanhamento e avaliação das políticas de saúde indígena por meio das instâncias de controle social, como os Conselhos Distritais de Saúde Indígena (CONDISI), Conselhos Locais de Saúde Indígena (CLSI) e Fórum Permanente dos Presidentes de CONDISI (FPCONDISI) (BRASIL, 2009; 2011), de acordo com a Portaria GM/MS n 755, de abril de 2012.

O Distrito Sanitário Especial Indígena (DSEI) caracteriza-se como uma unidade gestora descentralizada do Subsistema de Atenção à Saúde Indígena (SASISUS). Isto é, o DSEI compõe uma forma de organização dos serviços prestados que é designado a um espaço etno-cultural dinâmico, geográfico, populacional e administrativo delimitado e específico. O DSEI contempla um conjunto de atividades técnicas, as quais visam medidas racionalizadas e qualificadas de atenção à saúde. Promove a reorganização da rede de saúde e também das práticas sanitárias, além de desenvolver atividades administrativo-gerenciais necessárias à prestação da assistência, com a ajuda do Controle Social (BRASIL, 2014b).

Atualmente no Brasil existem 34 Distritos Sanitários Especiais Indígenas que são divididos estrategicamente por critérios territoriais, todavia não necessariamente são divididos por estados, de acordo Figura 1. 
Figura 1. Mapa dos Distritos Sanitários Especiais Indígenas- DSEI.

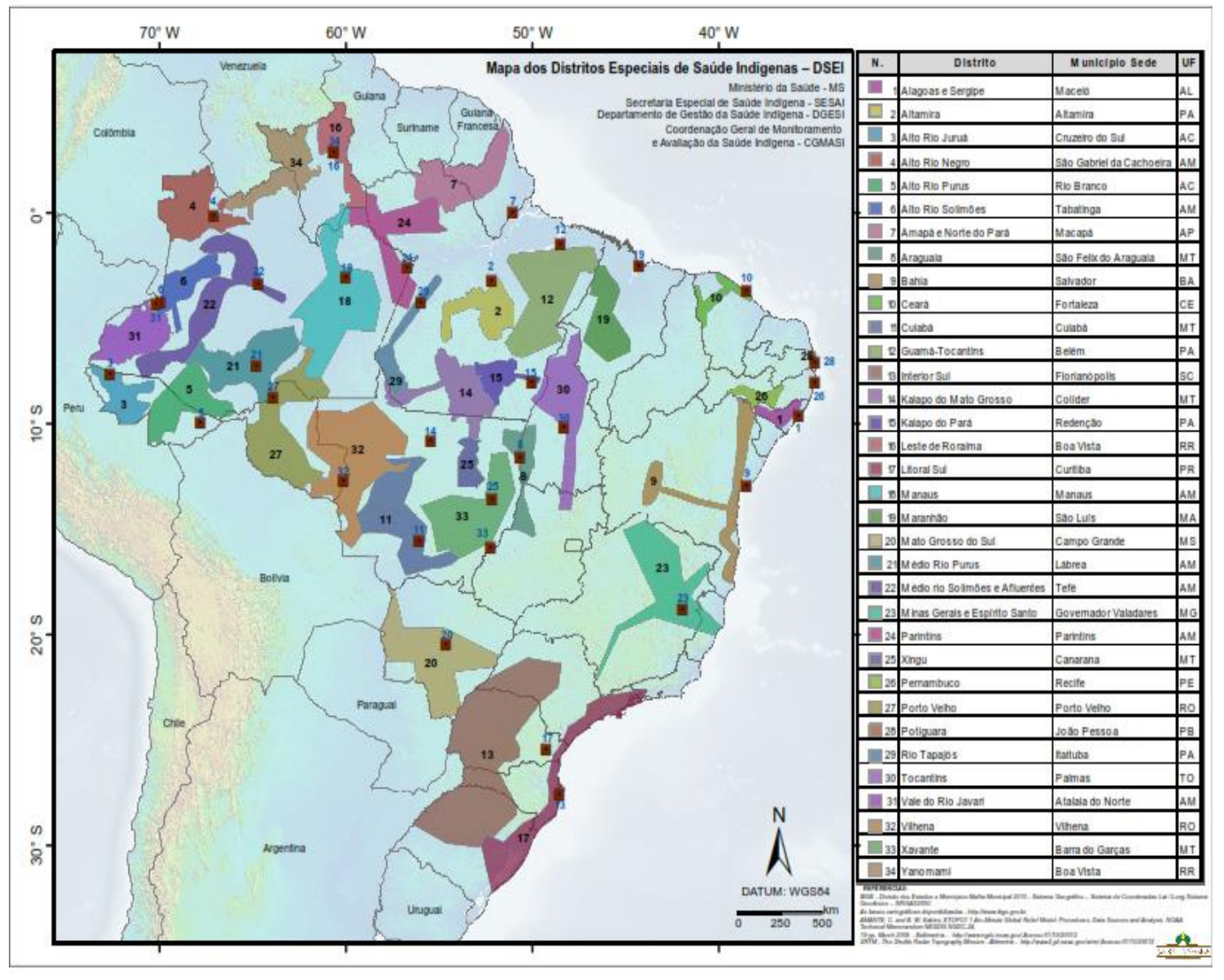

Fonte: SESAI/MS

Atualmente, a população geral indígena do Brasil encontra-se em torno de 817.963 habitantes (IBGE, 2010) e destes, 665.750 localizam-se em aldeias (SIASI/MS, 2015), distribuídos em 305 povos que falam 274 línguas (IBGE, 2010). Esses povos estão distribuídos em todos os 26 estados, no Distrito Federal e em 498 municípios, sendo $11 \%$ de médio porte (acima de 80 Mil Habitantes) e $50 \%$ de pequeno porte (menos de 20 Mil Habitantes), sendo em 688 terras indígenas e do território geral, onde localizam-se 5.625 aldeias, 60,46\% são regularizadas (SIASI/MS, 2015).

A organização do DSEI e o modelo assistencial da saúde indígena são estruturados e compostos por postos de saúde, com os Polos Base e as Casas de Saúde Indígena (CASAI), conforme Figura 2. 
Figura 2 - Organização do DSEI e Modelo Assistencial da Saúde Indígena

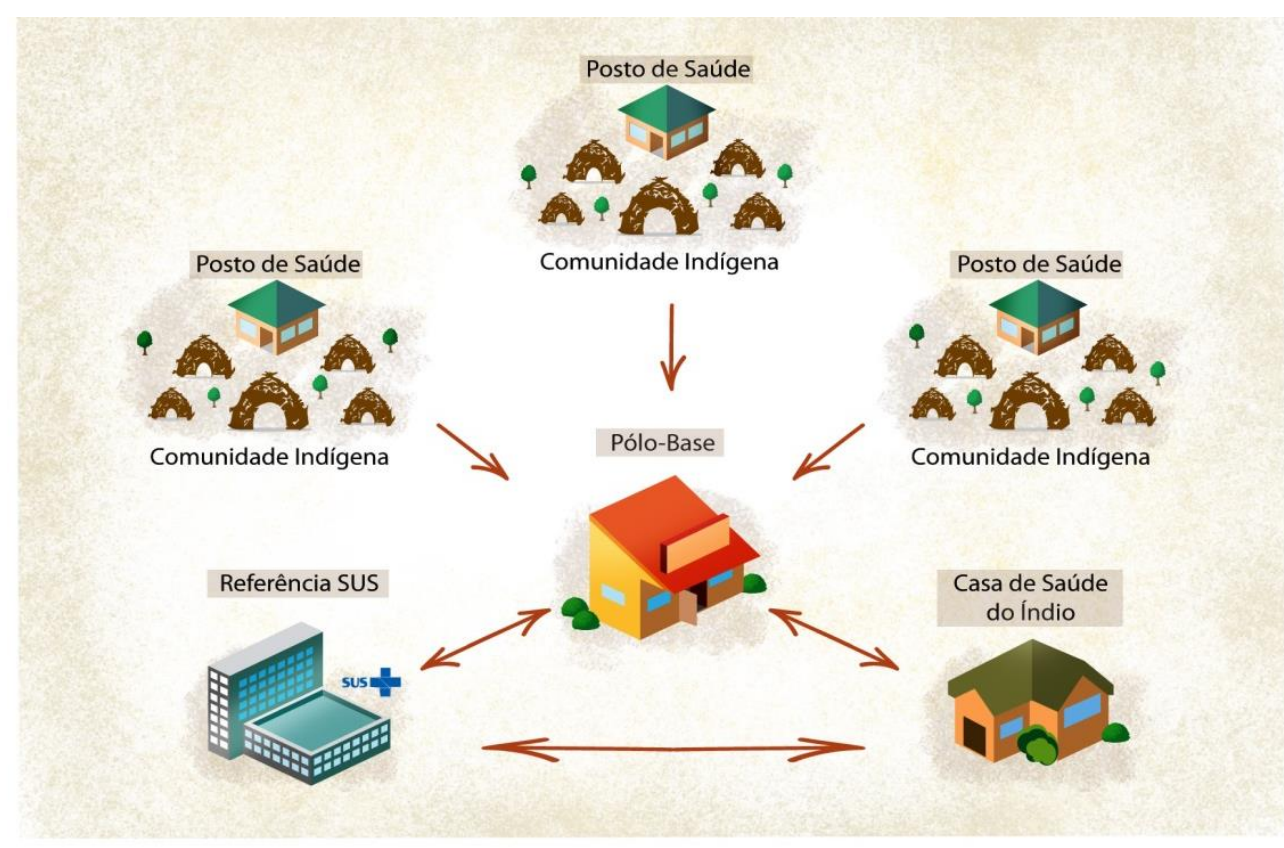

Fonte: SESAI/MS.

A Constituição Federal de 1988 e a Lei n ${ }^{\circ} 8.142 / 1990$ permite à sociedade brasileira o direito de participar tanto do planejamento, quanto da fiscalização da saúde por meio do controle social. Essa lei dispõe sobre a participação do cidadão brasileiro na gestão do Sistema Único de Saúde e sobre as transferências intergovernamentais dos recursos financeiros na esfera da saúde (BRASIL, 1990).

Essa mesma lei também descreve que o SUS contará, em cada esfera de governo e sem prejuízo das funções do Poder Legislativo, com instâncias colegiadas, como as Conferências de Saúde e os Conselhos de Saúde. Assim sendo, por meio desses mecanismos de participação, os usuários do sistema tem a oportunidade de participação em todas as etapas de operacionalização do SUS, configurado como um controle externo exercido pelos cidadãos (BRASIL, 2011).

Convocadas pelo Poder Executivo ou, extraordinariamente, por esta ou pelo Conselho de Saúde, as Conferências de Saúde poderão ocorrer a cada quatro anos. As 
Conferências são fóruns que reúnem representantes dos vários segmentos sociais, dentre eles, usuários, trabalhadores, prestadores de serviço e gestores para discutirem, avaliarem a situação da saúde e propor diretrizes para a formulação da politica de saúde (BRASIL, 2011).

Já os Conselhos de Saúde são órgãos colegiados de caráter permanente e deliberativo e atuam na formulação, avaliação, fiscalização, supervisão e deliberação das políticas públicas de saúde. A estrutura dessas instâncias possui composição paritária representado por $50 \%$ dos segmentos dos usuários, $25 \%$ do segmento gestores públicos e privados e $25 \%$ do segmento dos trabalhadores da saúde, definido pela Resolução do Conselho Nacional de Saúde (CNS) n 453, de 2012 (BRASIL, 2011).

Além disso, os Conselhos de Saúde são regidos por regras de funcionamento descritas em um regimento interno. Esse regimento deve obedecer aos princípios básicos estabelecidos nas Leis no 8.080/1990 e nº 8.142/1990, na Resolução do CNS n ${ }^{\circ}$ $453 / 2012$.

Com a criação da Lei Arouca é instituído o Subsistema de Atenção à Saúde Indígena no Sistema Único de Saúde (SASISUS) que garante condições para a promoção de saúde e as ações relacionadas à atenção integral aos povos indígenas, além de garantir a participação dos indígenas nos órgãos colegiados de formulação, acompanhamento e avaliação das políticas públicas de saúde que valorize as especificidades culturais, históricas, geográficas e epidemiológicas dessa população (BRASIL, 1999).

Para tanto, como no SUS, foram institucionalizadas a forma de organização das instâncias de controle social da saúde indígena, por meio da Portaria GM/MS n ${ }^{\circ}$ 755/2012: Conselho Distrital de Saúde Indígena (CONDISI), Conselho Local de Saúde 
Indígena (CLSI) e Fórum de Presidentes de Conselhos Distritais de Saúde Indígena (FPCONDISI), (BRASIL, 2012). Essas instâncias de controle social também está sobre o regramento da a Resolução n ${ }^{\circ} 453$, de 10 de maio de 2012 do Conselho Nacional de Saúde, que dispõe sobre as diretrizes para estruturação, formulação e funcionamento dos Conselhos de Saúde (BRASIL, 2009; 2012).

Os Conselhos Locais de Saúde Indígena são instâncias permanentes e consultivas, formadas somente por indígenas que se organizam por aldeia ou por um conjunto de aldeias que fiscalizam como as ações e serviços de saúde estão sendo implementadas (BRASIL, 2012). Os encontros ocorrem de acordo com a organização de cada CLSI e podem ocorrer nas aldeias, Polo Base ou municípios, onde os conselheiros indígenas participam da discussão e da elaboração de propostas nas áreas de atenção à saúde, controle social, edificações e saneamento em terras indígenas, na área das aldeias de abrangência do CLSI. Essas discussões a nível local servirão de subsídio para as discussões no nível distrital, nos Conselhos Distritais de Saúde Indígena (BRASIL, 2009). O número de membros de cada Conselho Local de Saúde Indígena será determinado pelos respectivos Conselhos Distritais de Saúde Indígena, pautando-se nos regimentos internos de cada região (BRASIL, 2012).

Os Conselhos Distritais de Saúde Indígena, por sua vez, possuem caráter deliberativo, tem como objetivo, participar na elaboração e aprovação do Plano Distrital de Saúde Indígena e acompanhar e avaliar sua execução, avaliar a execução das ações de atenção integral à saúde indígena; e apreciar e emitir parecer sobre a prestação de contas dos DSEI ( BRASIL, 2012). 
Essa instância é composta por 50\% de representantes dos usuários indígenas, eleitos pelas respectivas comunidades indígenas da área de abrangência de cada DSEI; $25 \%$ de representantes dos trabalhadores que atuam na atenção à saúde indígena no respectivo DSEI e em órgãos do SUS que executam ações de apoio complementar na atenção à saúde indígena das comunidades indígenas atendidas no respectivo DSEI, todos eleitos pelos trabalhadores; e 25\% de representantes dos governos municipais, estaduais, federal e prestadores de serviços na área de saúde indígena, conforme o caso, nos limites de abrangência de cada DSEI, todos indicados pelos dirigentes dos respectivos órgãos que representam (BRASIL, 2013).

Outra instância de controle social na saúde indígena é o Fórum de Presidentes de Conselhos Distritais de Saúde Indígena, instituído pela Portaria nº 644 GM/MS, de 27 de março de 2006. Essa instância tem caráter consultivo, propositivo e analítico e é a instância máxima de assessoramento da SESAI em relação às Políticas de Atenção à Saúde dos Povos Indígenas. Dessa maneira, está em consonância com as instâncias decisórias do SUS, com base nas diretrizes estabelecidas nas Conferências Nacionais de Saúde e nas Conferências Nacionais de Saúde Indígena, sem prejuízo das competências deliberativas do Conselho Nacional de Saúde (BRASIL, 2009).

\section{Sobre as Conferências Nacionais de Saúde Indígena.}

A $1^{\mathrm{a}}$ Conferência Nacional de Proteção à Saúde do Índio (CNPSI), realizada em Brasília, em 1986, foi um desdobramento da $8^{\text {a }}$ Conferência Nacional de Saúde, responsável pela formulação do Sistema Único de Saúde (SUS). Primeiro evento de caráter nacional com legitimidade para discutir política de saúde dos povos indígenas. 
Seu relatório apesar de sintético e registrando poucas diretrizes, trouxe elementos fundamentais de como deveria ser a gestão e a organização da assistência à saúde dos povos indígenas e de principalmente o protagonismo desses povos na formulação, no acompanhamento e nas tomadas de decisões referentes a politica de saúde (BRASIL, 2015). Além de atribuir a responsabilidade da saúde indígena a esfera federal, ou seja, ao Ministério da Saúde (MS).

A $2^{\mathrm{a}}$ Conferência Nacional de Saúde para os Povos Indígenas (2a CNSPI), que ocorreu em Luziânia/GO, 1993, veio consolidar o processo político deflagrado na $1^{\text {a }}$ CNPSI, como a definição dos princípios e diretrizes do modelo de atenção diferenciado para a saúde do índio, (BRASIL, 2015).

Segundo Martins (2013), as conclusões da $2^{\text {a }}$ CNPSI, haviam ratificado as recomendações da conferência anterior de que a gestão da saúde indígena deve ser de responsabilidade do Ministério da Saúde, ao mesmo tempo em que reivindicaram maior participação social no processo decisório, investimentos em infraestrutura e qualificação de recursos humanos e a adoção de um modelo de atenção diferenciado.

Entre os princípios básicos do Modelo de Assistência Diferenciado para a Saúde do Índio, destacou-se a necessidade de adequação do Sistema Único de Saúde às especificidades dos povos indígenas. A segunda conferência apontou objetivos quanto a definição de diretrizes para a política nacional, bem como atualizou recomendações aprovadas durante a ${ }^{\mathrm{a}} \mathrm{CNPSI}$, que direcionou o que futuramente viria ser o Subsistema de Atenção à Saúde dos Povos Indígenas (BRASIL,2015). 
Com o Relatório da 2a CNSPI em mãos, o deputado Sérgio Arouca apresentou ao Congresso Nacional o Projeto de Lei $n^{\circ}$ 63/1997 que somente em 1999 foi transformado em Lei que criou o Subsistema de Atenção à Saúde dos Povos Indígenas.

A $3^{\text {a }}$ Conferência Nacional de Saúde Indígena ( $3^{\mathrm{a}} \mathrm{CNSI}$ ), também ocorreu na cidade de Luziânia, estado de Goiás, no período de 14 a 18 de maio de 2001, cujo tema foi "Efetivando o SUS: Acesso, Qualidade e Humanização na Atenção à Saúde Indígena, com controle social", convocada pela Resolução n 305 e teve como finalidade analisar os obstáculos e os avanços do Sistema Único de Saúde na implantação dos Distritos Sanitários Especiais Indígenas e propor diretrizes para a sua efetivação (BRASIL, 2015).

Nessa terceira conferência pôde-se observar o processo ascendente nos debates e elaboração das propostas, começando pelas etapas locais e distritais, para em fim seguir para etapa nacional, que contou com cerca de mil participantes, proporcionando a participação ativa dos usuários indígenas e dos profissionais de saúde.

Após 20 anos da realização da primeira Conferência, chegavam ao município de Rio Quente 1.228 representantes de mais de 100 etnias, dos 34 distritos sanitários indígenas. Recomendada pela $12^{\mathrm{a}}$ Conferência Nacional de Saúde, a $4^{\mathrm{a}}$ Conferência Nacional de Saúde Indígena (4 CNSI) ocorreu no período de 27 a 31 de março de 2006, com o tema “ Distrito Sanitário Especial Indígena, Território de Produção de Saúde, Proteção da Vida e Valorização das Tradições ( BRASIL, 2015).

Durante a conferência dentre as discussões previstas no documento orientador, houve debate intenso, sobre a possível mudança da gestão da saúde indígena da Fundação Nacional de Saúde para um órgão da administração direta do Ministério da 
Saúde, sob regime de votação ficou aprovado que a saúde indígena permaneceria sob coordenação da FUNASA

Passaram-se sete anos para realização da $5^{\text {a }}$ Conferência Nacional de Saúde Indígena (5ª CNSI) que ocorreu em Brasília, no período de 2 a 6 de dezembro de 2013, com o tema "Subsistema de Atenção à Saúde Indígena e o SUS: Direito, Acesso, Diversidade e Atenção Diferenciada" (BRASIL, 2015).

A $5^{a}$ CNSI foi a primeira conferência após a mudança da gestão da saúde indígena da FUNASA para a SESAI, órgão da administração direta do Ministério da Saúde criada em 20 de outubro de 2010 para coordenar o SASISUS. Essa conferência de destacou por ser um marco na história das lutas dos 305 povos indígenas do Brasil por uma saúde pública de qualidade, principalmente por ter tido uma ampla participação das comunidades indígenas nos debates para sua preparação. Foram 306 conferências locais, nos 34 Distritos Sanitários Especiais Indígenas, que estão localizados em 24 estados e 560 municípios da Federação, envolvendo mais de 23 mil participantes (BRASIL, 2015).

Diferente das conferências anteriores, a $5^{\mathrm{a}} \mathrm{CNSI}$ além de debater e propor novas diretrizes para a reformulação da PNASPI, ela trouxe mais intensamente o debate quanto a desburocratização da gestão da saúde indígena, com a aprovação de moção que norteou o governo a elaborar uma proposta de criação Instituto Nacional de Saúde Indígena (INSI), novo modelo de gestão descrito no artigo de Souza et.al (2015), que atualmente encontra-se tramitando através do Projeto de Lei ${ }^{\circ}$ 3501/2015 no Congresso Nacional, além da aprovação por unanimidade a gestão da SESAI e da 
repulsa em relação as indicações políticas partidárias para ocuparem os cargos comissionados da saúde indígena. 


\section{RESULTADOS E DISCUSSÕES.}

Os resultados e discussões serão apresentados em formato de artigo.

Título: Estruturação do Controle Social após a criação da Secretaria Especial De Saúde Indígena: mobilização, representatividade e (r)evolução.

Submissão: Revista Tempus Actas de Saúde Coletiva, da Universidade de Brasília, conforme termo de submissão.

Autores: Bianca Coelho Moura, Antônio Alves de Souza, Edson Oliveira Pereira, Ana Valéria Machado Mendonça, Maria Fátima de Sousa. 
ESTRUTURAÇÃO DO CONTROLE SOCIAL APÓS A CRIAÇÃO DA SECRETARIA ESPECIAL DE SAÚDE INDÍGENA: MOBILIZAÇÃO, REPRESENTATIVIDADE E (R)EVOLUÇÃO.

CONTROL STRUCTURE SOCIAL AFTER THE ESTABLISHMENT OF THE SPECIAL SECRETARIAT OF INDIGENOUS HEALTH: MOBILIZATION, REPRESENTATION AND (R)EVOLUTION.

ESTRUCTURA DE CONTROL SOCIAL DESPUÉS DEL ESTABLECIMIENTO DE LA SECRETARÍA ESPECIAL DE SALUD INDÍGENA: MOVILIZACIÓN, REPRESENTACIÓN Y (R)EVOLUCIÓN.

\section{RESUMO}

O presente artigo objetiva avaliar a estruturação do controle social da saúde indígena, demonstrando as etapas percorridas pelos povos indígenas após a criação da Secretaria Especial de Saúde Indígena no Ministério da Saúde, analisando os processos participativos, incluindo os investimentos disponibilizados para essas ações. Para coleta de dados foram utilizadas as fontes de base secundária existentes oficialmente no âmbito da secretaria em estudo, que compreendem cópias de documentos oficiais (atas, relatórios e processos) do controle social para levantamento quantitativo para subsidiar as discussões qualitativas detalhadas na metodologia. Os resultados apontam um fortalecimento nas ações de controle social da saúde indígena e, ainda, uma valorização dos espaços de controle, promovendo a institucionalização e estruturação, além do crescimento e desenvolvimento organizacional que melhor caracterizasse o Controle Social como instrumento de governo, da qualificação e capacitação dos conselheiros e no investimento, de forma gradativa, no período de 2011 a 2015, o que refletiu diretamente nas ações de melhor qualificação e desenvolvimento do controle social.

Palavras Chave: Controle Social; Saúde Indígena; Políticas Públicas; Gestão em Saúde.

\section{ABSTRACT}

This article aims to evaluate the structure of social control of indigenous health, demonstrating the steps taken by indigenous peoples after the creation of the Special 
Secretariat of Indigenous Health in the Ministry of Health, analyzing participatory processes, including investments available for these actions. For data collection were used existing secondary basic sources officially within the secretariat study, which include copies of official documents (minutes, reports and processes) of social control for quantitative survey to support the detailed discussions qualitative methodology. The results point to a strengthening in social control actions of indigenous health and also an appreciation of space control, promoting the institutionalization and structuring in addition to the growth and organizational development that best characterize the social control as a government instrument, qualification and training of counselors and investment, gradually, in the period 2011-2015, which directly reflected in the actions of better training and development of social control.

Keywords: Social Control; Indigenous health; Public policy; Health Management.

\section{RESUMEN}

Este artículo tiene como objetivo evaluar la estructura del control social de la salud de los indígenas, que demuestra las medidas adoptadas por los indígenas después de la creación de la Secretaría Especial de Salud Indígena del Ministerio de Salud, el análisis de los procesos de participación, incluidas las inversiones disponibles para estas acciones. Para la recolección de datos se utilizaron fuentes secundarias básicas oficialmente dentro del estudio de la secretaría, que incluyen copias de documentos oficiales (actas, informes y procesos de control social) para la encuesta cuantitativa para apoyar las discusiones detalladas metodología cualitativa existente. Los resultados apuntan a un fortalecimiento de las acciones de control social de la salud indígena y también una apreciación de control del espacio, la promoción de la institucionalización y estructuración, además del crecimiento y desarrollo de la organización que mejor caracteriza el control social como un instrumento de gobierno, cualificación y formación de asesores de inversión y, poco a poco, en el periodo 2011-2015, lo que refleja directamente en las acciones de mejora de la formación y el desarrollo del control social.

Palabras Clave: Control Social; Salud de los indígenas; Políticas públicas; Gestión de la Salud. 


\section{INTRODUÇÃO}

Gestão democrática não é só um princípio pedagógico, é também um preceito constitucional. O parágrafo único do artigo primeiro da Constituição Federal de 1988 estabelece como cláusula pétrea que "todo o poder emana do povo, que o exerce por meio de representantes eleitos ou diretamente", consagrando uma nova ordem jurídica e política no país com base em dois pilares: a democracia representativa (indireta) e a democracia participativa (direta), entendendo a participação social e popular como princípio inerente à democracia (BRASIL, 1988).

Comecemos pela relação e pela diferença entre Participação Social e Participação Popular. Participação Social se dá nos espaços e mecanismos do controle social como nas conferências, conselhos, ouvidorias, audiências públicas, entre outros. São os espaços e formas de organização e atuação da Participação Social. É assim que ela é entendida, como categoria e como conceito metodológico e político, pelos gestores públicos que a promovem. Essa forma de atuação da sociedade civil organizada é fundamental para o controle, a fiscalização, o acompanhamento e a implementação das políticas públicas, bem como para o exercício do diálogo e de uma relação mais orgânica entre os governos e a sociedade civil (GADOTTI, 2014).

A Participação Popular, por outro lado, corresponde às formas mais independentes e autônomas de organização e de atuação política dos grupos das classes populares e trabalhadoras e que se constituem em movimentos sociais, associações de moradores e lutas sindicais. A Participação Popular corresponde a formas de luta mais direta do que a participação social, por meio de ocupações, marchas, lutas comunitárias, entre outros. Embora dialogando e negociando pontualmente com os governos, em determinados momentos, essas formas de organização e mobilização não atuam dentro de programas públicos e nem se subordinam às suas regras e regulamentos.

No campo da saúde, na realização, em 1986, da $8^{a}$ Conferência Nacional de Saúde, houve uma intensa participação popular e que foi um marco no processo de reformulação da política de saúde brasileira, onde foram lançados os princípios básicos e as diretrizes para um novo sistema de saúde, o Sistema Único de Saúde (SUS). Neste mesmo ano, em novembro, cumprindo deliberação da $8^{\text {a }}$ Conferência Nacional de Saúde, ocorreu a I Conferência Nacional de Proteção à Saúde do Índio (NOVO, 2011). 
A referida Conferência foi o primeiro evento de caráter nacional que contou com representações indígenas da maioria das etnias do Brasil para discutir a política de saúde dos povos indígenas brasileiros.

Nove anos após a publicação das Leis Orgânicas da Saúde em 1990 é sancionada a Lei n ${ }^{\circ}$ 9.836, de 23 de setembro de 1999, que cria o Subsistema de Atenção à Saúde Indígena (SASISUS), dispondo que "as populações indígenas devem ter acesso garantido ao SUS" (BRASIL, 1999). Além de possuir o direito de participarem da formulação, acompanhamento e avaliação das políticas de saúde, por meio dos conselhos de saúde.

Em 2002, foi publicada a Política Nacional de Atenção a Saúde dos Povos Indígenas (PNASPI), pela Portaria GM no 254, de 31 de janeiro de 2002, que dispõe sobre a adoção de um modelo complementar e diferenciado de organização dos serviços voltados para proteção, promoção e recuperação da saúde e que garante aos povos indígenas participação na formulação e aperfeiçoamento da política (BRASIL, 2002).

É na PNASPI que encontramos a primeira referência aos Conselhos Locais e Distritais da Saúde Indígena, onde a participação indígena deverá ocorrer em todas as etapas do planejamento, implantação e funcionamento dos Distritos Sanitários Especiais Indígenas (DSEI), contemplando expressões formais e informais (RODRIGUES, 2012). A comunidade indígena exerce sua participação no Subsistema de Atenção à Saúde Indígena propondo diretrizes e atuando na fiscalização da execução da Política Nacional de Atenção à Saúde dos Povos Indígenas, em todos os níveis, por meio da constituição de Conselhos Locais, Distritais de Saúde Indígena e pelo Fórum de Presidentes dos Conselhos Distritais; pelas Conferências Nacionais de Saúde e de Saúde Indígena; e pela presença de representantes indígenas nos conselhos nacional, estaduais e municipais de saúde (BRASIL, 2002).

Segundo a Portaria $\mathrm{n}^{\mathrm{o}} 755$, de 18 de abril de 2012, o controle social do SASISUS está organizado em três instâncias, sendo elas: Conselho Local de Saúde Indígena (CLSI), Conselho Distrital de Saúde Indígena (CONDISI) e o Fórum de Presidentes dos Conselhos Distritais de Saúde Indígena (FPCONDISI) (BRASIL, 2012).

$\mathrm{Na}$ esfera local e distrital, o controle social é exercido respectivamente pelos Conselhos Locais e Distritais de Saúde Indígena. Os Conselhos Locais de Saúde Indígena, de caráter consultivo, são compostos apenas por representantes indígenas. 
Já os Conselhos Distritais de Saúde Indígena são de caráter deliberativo, têm composição paritária de $50 \%$ de usuários, $25 \%$ de prestadores de serviço e gestores e $25 \%$ de trabalhadores de saúde do respectivo DSEI. Em âmbito nacional, há o Fórum de Presidentes dos CONDISI, de caráter consultivo, o qual reúne os presidentes dos 34 Conselhos Distritais de Saúde Indígena e é responsável por acompanhar e avaliar de forma mais ampla o Subsistema de Atenção à Saúde Indígena (BRASIL, 2012).

\section{Representação social na saúde indígena: uma história recente.}

A Lei $\mathrm{n}^{\mathrm{o}}$ 8.142, de 28 de dezembro de 1990, define a participação da comunidade na gestão do Sistema Único de Saúde (SUS) e no seu artigo $1^{\circ}$ define "as instâncias colegiadas de controle social: I) a Conferência de Saúde, e II) o Conselho de Saúde”. O Subsistema de Atenção a Saúde Indígena, por ser vinculado ao Sistema Único de Saúde, também adota medidas de controle e participação social, de acordo com a Lei no 9.836/99, que dispõe sobre as condições para a promoção de saúde e as ações relacionadas à atenção integral aos povos indígenas.

No campo da saúde, uma exigência de mudança estrutural foi representada pelo Movimento de Reforma Sanitária, tendo uma importante contribuição na conjuntura de estabilização da ordem política. A questão da implantação da Reforma Sanitária foi tema de discussão na $8^{\text {a }}$ Conferência Nacional de Saúde realizada em Brasília em 1986, no período da chamada Nova República. Esse evento reuniu cerca de quatro mil pessoas entre diversos segmentos sociais, sendo considerado um marco na história da política de saúde no país, devido a forte participação da sociedade civil e os debates que serviram de base para a construção do SUS.

Nessa mesma dimensão aponta Correia (2000, p. 55), o "controle social passa a existir, como a possibilidade dos movimentos sociais influenciarem as políticas públicas de forma que atendam as necessidades da população, durante o processo de democratização do país". Sempre na perspectiva da descentralização e uma real participação da sociedade civil na gestão das políticas públicas, através do controle social como mecanismo de gestão do SUS.

O controle social é, na história da Política de Saúde, um dos campos que construiu visibilidade para os movimentos sociais na saúde, quer seja nas denúncias das 
"ausências e omissões" dos serviços instalados, ou pela necessidade de construir espaços para o exercício do controle nos serviços e nas burocracias da gestão da saúde (SPOSATI; LOBO, 1992, p. 366).

A implementação e a execução de uma política pública que venha efetivamente responder as necessidades e demandas da sociedade dependem, efetivamente, do exercício do controle social por parte da sociedade civil. É nesta perspectiva que o papel dos conselhos nas discussões, elaborações de planos e projetos, bem como a fiscalização das políticas públicas é fundamental.

Estudos realizados por Silva e Almeida (2011) apontam que desde a institucionalização do Sistema Único de Saúde a descentralização, o financiamento, o controle social e os recursos humanos têm ocupado importantes agendas dos gestores e têm sido ressaltadas como fundamentais para a sua implementação: a descentralização, o financiamento, o controle social e os recursos humanos.

Carvalho (1995) alega que a questão da segmentação social possui uma associação clara com a doutrina marxista, não só pela questão da distribuição dos problemas de saúde, mas como uma "chave" para sua explicação. Nesse contexto, Correia (2000) afirma que os conselhos populares de saúde se constituem nas primeiras formas de interação entre Estado e sociedade na área da saúde.

A Portaria $\mathrm{n}^{\mathrm{o}}$ 755, de 18 de abril de 2012, que dispõe sobre a organização do controle social no Subsistema de Atenção à Saúde Indígena, garante a participação indígena nos órgãos colegiados de formulação, acompanhamento e avaliação das políticas públicas de saúde, que são os conselhos de saúde. No âmbito da saúde indígena, as instâncias colegiadas do controle social são constituídas pelo Conselho Local de Saúde Indígena (permanente, consultivo e propositivo), Conselho Distrital de Saúde Indígena (permanente, paritário e deliberativo) e Fórum de Presidentes do CONDISI (permanente, consultivo e propositivo) (BRASIL, 2012).

Carvalho (1995) ao analisar a importância da participação popular no controle social, afirma que o protagonismo da participação deixa de ser o serviço de saúde, ultrapassa os limites do setor e alcança o conjunto da sociedade e do Estado. E é nesse plano que se definem seus novos objetivos: a democratização da saúde, designando a reivindicação 
pelo acesso universal e igualitário aos serviços e também pelo acesso ao poder (CARVALHO, 1995, p. 22).

Os conselhos Locais de Saúde Indígena são compostos apenas por indígenas e é uma instância permanente, propositiva e consultiva que debate e encaminha aos gestores as discussões pertinentes às ações e aos serviços de saúde em seu âmbito de abrangência, possuindo competências dentre os diversos setores e ações em âmbito local.

O acompanhamento, a avaliação e manifestação quanto à execução das ações de atenção à saúde indígena desempenhadas na sua comunidade realizada pelo CLSI visa garantir nos preceitos da lei que regulamenta a participação social, um controle social sistemático e capilarizado. De forma que todas as ações sejam acompanhadas por representantes que conhecem a realidade local e, ainda, que possuam um grau de representatividade e respeito dentro do ambiente comunitário pelo qual ele acompanha e representa.

Além disso, visando garantir e fortalecer o elo com a instância de maior hierarquia é o CLSI quem elege os conselheiros representantes das comunidades indígenas para integrarem o respectivo Conselho Distrital de Saúde Indígena e Conselho Municipal de Saúde, sendo que depois desse processo se responsabiliza em fazer recomendações ao Conselho Distrital de Saúde Indígena por intermédio dos conselheiros eleitos. Possuindo autonomia para aprovar ou modificar seu próprio Regimento Interno, adequando-o sempre que houver necessidade, claro, com transparência e participação popular, justificada pelo bem maior de sua comunidade.

Já os Conselhos Distritais de Saúde Indígena, de acordo a Portaria nº 755/2012, são constituídos legalmente nos 34 Distritos Sanitários Especiais Indígenas (DSEI) e apresentam caráter permanente e deliberativo, são compostos paritariamente por usuários (50\%), trabalhadores (25\%) e gestores/prestadores de serviço em saúde (25\%), sendo suas competências mais regionalizadas e com um leque cultural juridiscrito mais amplo, uma vez que um Distrito Especial de Saúde Indígena engloba na sua grande maioria múltiplas etnias com culturas e tradições diversas. 
Cabe a esses conselhos proporem diretrizes gerais e específicas no campo da saúde indígena a serem aplicadas na área de abrangência de cada DSEI; planejar, fiscalizar e acompanhar a execução das ações de edificações e saneamento básico em aldeias e de atenção à saúde indígena, com enfoque intersetorial e interinstitucional, respeitando as diferenças culturais, necessidades e os interesses de cada comunidade; apoiar e defender as práticas e rituais dos povos indígenas, buscando conciliar a prática da medicina ocidental com as da medicina tradicional indígena; propor, defender, apoiar e acompanhar iniciativas de ações de atenção à saúde e de valorização dos direitos dos povos indígenas no âmbito da saúde; aprovar, acompanhar, supervisionar, fiscalizar e avaliar o desenvolvimento de ações previstas no Plano Distrital de Saúde Indígena do DSEI; acompanhar a aplicação e aprovar a prestação de contas de recursos oriundos de órgãos públicos; articular e apoiar as ações dos Conselhos Locais de Saúde Indígena; receber, analisar, avaliar e dar encaminhamento às denúncias, reivindicações, recomendações e moções das comunidades indígenas e dos Conselhos Locais de Saúde Indígena, requerendo providências ou intervenção quando for necessário;

Compete também aos CONDISI analisar, avaliar os projetos de pesquisa que necessitem de anuência do CONDISI, consultar e informar as aldeias, quando for o caso, e encaminhar ao Fórum de Presidentes de Conselhos Distritais de Saúde indígena para conhecimento e acompanhamento; articular junto à gestão do DSEI a participação de membros do CONDISI e CLSI em reuniões, cursos, seminários, conferências, congressos, mesas redondas, oficinas de trabalho e outros eventos sobre assuntos pertinentes à saúde indígena, quando necessário; acompanhar a política de Recursos Humanos no âmbito do DSEI; participar do processo de preparação da Conferência Nacional de Saúde Indígena; indicar o Conselheiro Distrital que representará o CONDISI no Conselho Estadual de Saúde na área de abrangência do DSEI; propor e aprovar Comissões, com a finalidade de assessorar o CONDISI nas ações de saúde indígena, se assim for necessário; aprovar ou modificar o Regimento Interno, com suas normas de organização e funcionamento, adequando-o sempre que houver necessidade; e manifestar-se sobre assuntos de sua competência, principalmente os casos omissos ao Regimento Interno. 
O Fórum de Presidentes de CONDISI é composto pelos presidentes dos 34 CONDISI sendo uma instância permanente, propositiva e consultiva que possui a missão de acompanhamentos mais amplos e influência mais global.

A Portaria $n^{\circ} 755 / 2012$ prescreve que o Fórum de Presidente do CONDISI deve acompanhar a execução da Política Nacional de Atenção à Saúde dos Povos Indígenas; contribuir na elaboração, implantação e implementação de normas, instrumentos e métodos necessários à gestão participativa e ao controle social no âmbito do Subsistema de Atenção à Saúde Indígena; apreciar e dar parecer sobre critérios que definam o padrão de qualidade, os parâmetros assistências e melhor resolutividade das ações e serviços de assistência à saúde indígena; tomar conhecimento e opinar sobre critérios estabelecidos para contratação ou celebração de convênios; receber, apreciar e opinar sobre relatórios de movimentação de recursos orçamentários e financeiros da Secretaria Especial de Saúde Indígena (SESAI), já analisado pelos setores técnicos de planejamento, orçamento e gestão do Ministério da Saúde; definir, acompanhar e monitorar as políticas de capacitação das instâncias de controle social na Saúde Indígena; acompanhar e monitorar a execução das proposições estabelecidas pela Conferência Nacional de Saúde Indígena; discutir questões referentes ao funcionamento regular dos Conselhos Locais e Distritais de Saúde Indígena; propor recomendações para a SESAI, visando o aperfeiçoamento das ações de controle social na saúde indígena; socializar informações e decisões relativas à gestão participativa e controle social; contribuir para a integração e a articulação das ações das diversas áreas da SESAI com o controle social nos Distritos Sanitários Especiais Indígenas, além de aprovar ou modificar o Regimento Interno, adequando-o sempre que houver necessidade.

Neste contexto, o foco desta pesquisa é a estruturação dos conselhos de saúde que representam o Controle Social da Saúde Indígena, objetivando demonstrar como se deu o seu processo de reestruturação, no que diz respeito aos aspectos legais após a criação da Secretaria Especial de Saúde Indígena, em 2010, analisando os processos participativos, incluindo os investimentos aplicados nessas ações. Com isto, poderão ser fornecidos subsídios que permitam uma análise ampla de forma a contribuir para a melhoria da gestão pública, a nível local, distrital, regional e nacional, no caso do 
Fórum de Presidentes do CONDISI, tecendo assim um panorama do controle social a partir das ações realizadas por eles.

\section{METODOLOGIA}

O presente estudo é de natureza quantiqualitativa, cuja complementariedade da realidade investigada, contribuiu para caracterizar e aprofundar a realidade pesquisada.

Como materiais da pesquisa, foram utilizadas as fontes secundárias que são as informações obtidas junto a Secretaria Especial de Saúde Indígena, do Ministério da Saúde, devidamente autorizadas (Anexo 1). As fontes secundárias envolvidas na Pesquisa Documental se basearam na lei de criação do Conselho e suas alterações, portarias, decretos, documentos oficiais, bem como, análise do atual Regimento Interno, da composição dos Conselhos, do levantamento de dados sobre a situação sócio-política e organizacional do controle social da saúde indígena.

As fontes documentais possibilitaram o conhecimento dos processos de mudanças que ocorreram na conjuntura social. Para realização desta pesquisa, foram utilizados instrumentos e técnicas de caráter quanti-qualitativo, objetivando um melhor conhecimento da realidade investigada, como a observação sistemática, através da qual se buscou conhecer o funcionamento do conselho, a dinâmica das discussões, a tomada de decisões, a fiscalização quanto à implementação das deliberações, dentre outros fatores complementares.

\section{RESULTADOS E DISCUSSÕES}

Existem vários estudos que avaliam a atuação e o exercício do controle social na saúde, entretanto há uma escassez de estudos sobre o controle social na saúde na perspectiva indígena, principalmente após a criação da SESAI, em 2010. A complexidade do conhecimento sobre os povos indígenas do Brasil aumenta pelo fato da heterogeneidade de suas representações. As diferentes etnias constituem povos que diferem nos hábitos e nas culturas, nas formas de organização social e política, nos rituais, nas cosmologias, nos mitos, nas formas de expressão artística, nas habitações, na maneira de se relacionarem com o ambiente em que vivem, dentre outras distinções. 
Da análise dos dados coletados junto a Secretaria Especial de Saúde Indígena, do Ministério da Saúde, emergiram três categorias principais: Organização e Caracterização do Controle Social; Qualificação dos Conselheiros e Investimentos.

\section{Organização e caracterização do Controle Social.}

Os dados encontrados demonstram que a organização estrutural do controle social da saúde indígena encontra-se amplamente distribuído e com larga cobertura de atuação. A institucionalização de um CONDISI por Distrito Sanitário Especial Indígena, conforme a Portaria $n^{\circ} 755 / 2012$, busca garantir uma representatividade considerável, dado o número de conselhos existentes.

Tabela1. Quantitativo dos conselhos nos âmbitos local, distrital e de fórum.

\begin{tabular}{|c|c|}
\hline $\begin{array}{c}\text { INSTÂNCIAS DE } \\
\text { CONTROLE } \\
\text { SOCIAL }\end{array}$ & QUANTIDADE \\
\hline CLSI. & 397 \\
\hline CONDISI. & 34 \\
\hline FPCONDISI. & 01 \\
\hline
\end{tabular}

Fonte: SESAI/MS,2015

Embora, nos últimos anos seu número esteja compatível e representativo, notase que logo após a criação da Secretaria Especial de Saúde Indígena, no período de 2011 a 2015, o número de conselheiros sofre um largo acréscimo, principalmente no âmbito do número dos conselheiros locais e distritais, o que pode ser associado ao aumento gradativo do investimento no Controle Social após a criação da SESAI.

Observa-se, ainda, com base nos dados analisados e categorizados, que nos últimos anos 125 etnias estão representadas no segmento usuário, o que corresponde $41 \%$ do total de povos reconhecidos pela Fundação Nacional do Índio e que nos segmentos trabalhador e gestor esse percentual é de $38,30 \%$ e $21 \%$ respectivamente.

Tabela 2. Quantitativo de conselheiros por conselho e fórum no período de 2011 a 2015. 


\begin{tabular}{|l|l|l|l|l|l|}
\hline $\begin{array}{l}\text { INSTÂNCIAS DE } \\
\text { CONTROLE } \\
\text { SOCIAL }\end{array}$ & $\mathbf{2 0 1 1}$ & $\mathbf{2 0 1 2}$ & $\mathbf{2 0 1 3}$ & $\mathbf{2 0 1 4}$ & $\mathbf{2 0 1 5 *}$ \\
\hline $\begin{array}{l}\text { CLSI/Número de } \\
\text { Conselheiros }\end{array}$ & 4.458 & 4.496 & 4.496 & 5.301 & 5.301 \\
\hline $\begin{array}{l}\text { CONDISI/ Número } \\
\text { de Conselheiros }\end{array}$ & 1.199 & 1.390 & 1.390 & 1.572 & 1.572 \\
\hline $\begin{array}{l}\text { FPCONDISI/Número } \\
\text { de Presidentes }\end{array}$ & 34 & 34 & 34 & 34 & 34 \\
\hline
\end{tabular}

* Dados parciais até agosto de 2015. Fonte: SESAI/MS,2015.

Nota-se, a partir da busca nos assentamentos da secretaria em estudo, que é garantido as representações periodicidade nas reuniões, sendo uma marca do Controle Social da Saúde Indígena indicada pela positivação do Governo Federal, em 2010, através do Decreto $\mathrm{n}^{\circ} 7.336$ de 20 de outubro de 2010, que institucionaliza a Secretaria Especial de Saúde Indígena.

Ao longo dos quatros anos, de 2011 a 2015, respectivamente, foram realizadas 2.636 reuniões nos Conselhos Locais de Saúde Indígena, 393 reuniões de Conselhos Distritais de Saúde Indígena e 26 do Fórum de Presidentes de CONDISI, representando tecnicamente uma consequência positiva do investimento por parte da gestão para fortalecimento do controle social da saúde indígena.

Quanto à disposição por sexo dentro das representações dos conselhos, podemos observar que ainda há predominância é o sexo masculino. O presente estudo não pretende aprofundar na representação de gênero dentro das instâncias de controle social da saúde indígena, porém, os dados apontados demonstra uma predominância do sexo masculino nas representações indígenas de usuários para o controle social na saúde desses povos.

Gráfico 1. Quantitativo por sexo dos segmentos que compõem o controle social da saúde indígena. 


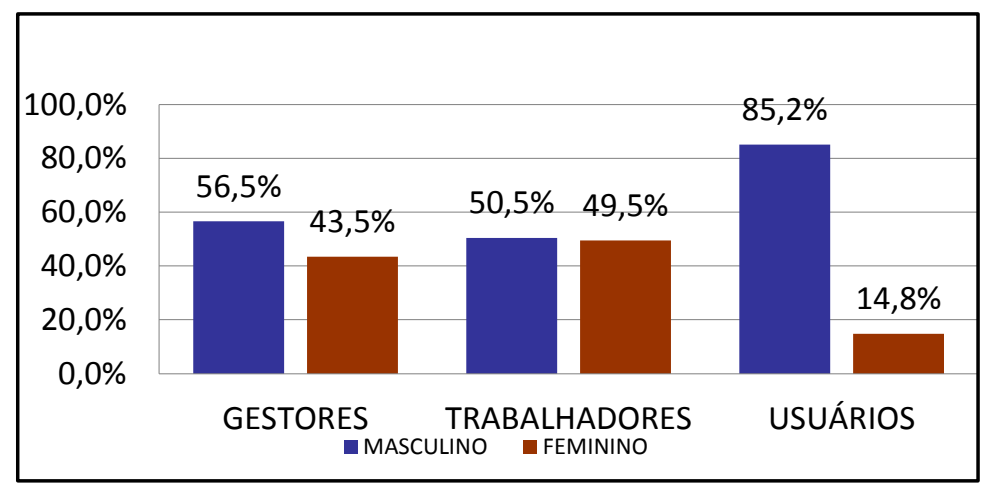

Fonte: SESAI/MS,2015.

Quanto ao perfil etário dos conselheiros, observa-se uma média de idade nos três segmentos (gestores, trabalhadores e usuários) que compõe o controle social indígena de 39 anos, sendo a maioria dos usuários da faixa etária de 40 a 54 anos, nota-se pouco envolvimento dos menores de 24 anos no controle social.

Gráfico 2. Faixa etária por segmento representativo do Controle Social Indígena.

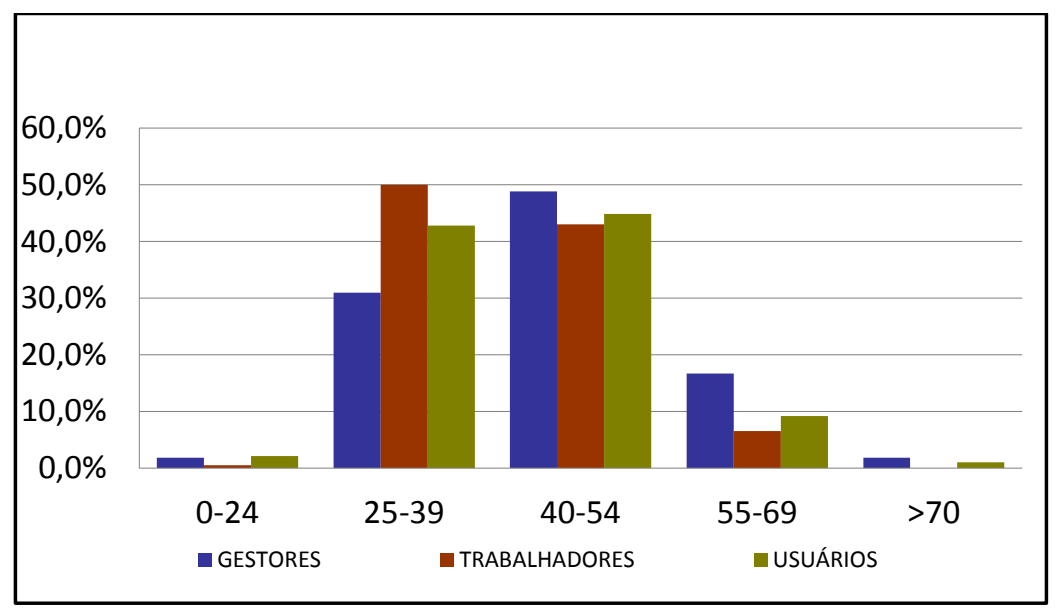

Fonte: SESAI/MS,2015.

A Política Nacional de Atenção à Saúde dos Povos Indígenas (2010), estabelece que as ações do controle social da saúde indígena não tratam apenas da prestação de serviços, elas podem se dá sobre diversos aspectos e decisões importantes, desde a definição de suas diretrizes até orientações mais gerais. O diagrama abaixo apresenta, de maneira genérica e esquemática, as etapas de atuação desde a detecção do fator problema até a avaliação de ações planejadas. O controle social pode ser realizado nestes diversos momentos da política pública, e de diversas formas.

Figura 1. Fluxo de processos do Controle Social Indígena por divisão de tarefas. 
1. Identificação de problema (CLSI)

(2.) Diagnóstico (CONDISI)

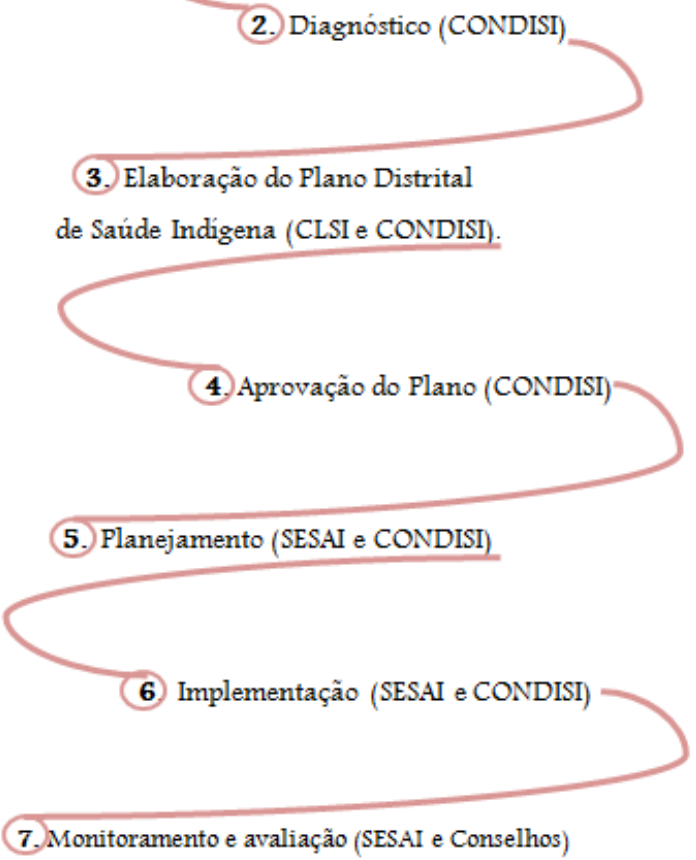

\section{Qualificação e Capacitação dos Conselheiros.}

Logicamente, os Conselheiros já entendem mesmo de forma leiga, ou não, como as pessoas de sua comunidade vivem, adoecem e morrem, além de conhecer sobre as doenças, suas causas e como evitá-las. É importante conhecer os problemas de saúde que o indivíduo adquire em função do meio ambiente e das condições de vida, que podem levar à incapacidade ou à morte, e os problemas de saúde provocados por causas externas como homicídios, atropelamentos, acidentes e suicídios.

Tabela 3. Quantitativo de conselheiros que receberam capacitação dentro do Subsistema de Atenção à Saúde Indígena do Sistema Único de Saúde no período de 2011 a 2015.

\begin{tabular}{|c|c|c|c|c|c|}
\hline $\begin{array}{c}\text { INSTÂNCIAS } \\
\text { DE CONTROLE } \\
\text { SOCIAL }\end{array}$ & 2011 & $\mathbf{2 0 1 2}$ & $\mathbf{2 0 1 3}$ & $\mathbf{2 0 1 4}$ & $\mathbf{2 0 1 5 ^ { * }}$ \\
\hline CLSI & 0 & 0 & 26 & 59 & 25 \\
\hline
\end{tabular}




\begin{tabular}{|c|c|c|c|c|c|}
\hline CONDISI & 0 & 0 & 7 & 19 & 08 \\
\hline FPCONDISI & 0 & 1 & 0 & 1 & 0 \\
\hline $\begin{array}{l}\text { Conselheiros } \\
\text { Capacitados }\end{array}$ & 0 & 102 & 963 & 2.174 & 1.010 \\
\hline
\end{tabular}

*Dados parciais até agosto de 2015. Fonte: SESAI/MS,2015.

Os dados apontam que não houve qualificação dos conselheiros durante o ano de 2011, justificado nos Relatórios de Gestão do Controle Social, do mesmo ano, pelo planejamento e elaboração dos conteúdos de qualificação para o controle social da saúde indígena com base na Política Nacional de Educação Permanente para o Controle Social no SUS, que culminou com a Oficina de Multiplicadores em 2012, para 102 participantes e em 2014 para 68 participantes - membros do FPCONDISI e Secretários Executivos dos CONDISI.

Estudos levantados por Ferreira (2012) apontam que a falta de capacitações dos conselheiros é citada como uma dificuldade dentro do controle social da saúde indígena em 2009. Na ocasião do estudo, apenas nove, dos 34 DSEI realizaram capacitações para conselheiros no ano 2009, e dois destes realizaram apenas capacitações para conselheiros locais.

Os resultados apresentados pela autora mostram que, para os entrevistados, uma das formas de melhorar o controle social é capacitar os conselheiros, pois a falta dela pode prejudicar a atuação dos conselheiros, sendo fundamental que eles entendam qual é o papel do controle social para que possam atuar de forma mais resolutiva e prática no ataque ao problema.

De acordo ao Plano de Ação do Controle Social (2013), as capacitações realizadas pelos Distritos Sanitários Especiais Indígenas e pela Secretaria Especial de Saúde Indígena observam as especificidades de cada segmento que o compõe, por entender que cada um acompanhará os objetos de sua responsabilidade, o que não impede que haja consultas mútuas e o trânsito entre as segmentações.

Gráfico 3. Distribuição de conselheiros dos conselhos distritais de saúde indígena por capacitação recebida. 


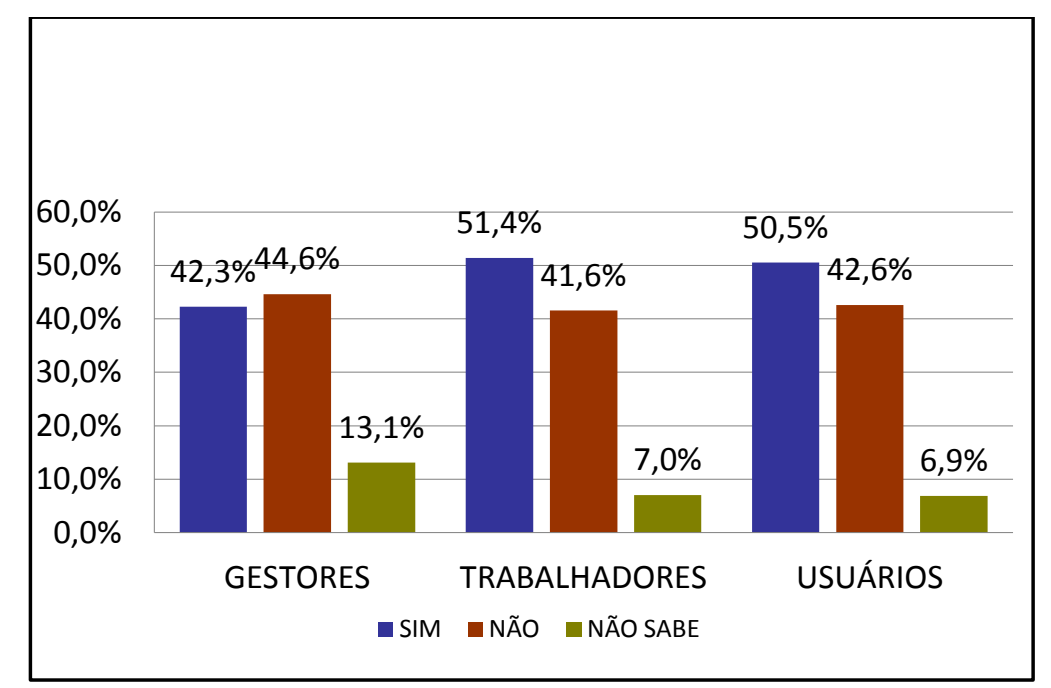

Fonte: SESAI/MS,2015.

É claro que, para uma efetiva participação do controle social, é importante conhecer os problemas da comunidade para estabelecer uma escala de prioridade. Dessa forma a comunidade discute no Conselho e em outras instâncias, objetivando a criação de políticas efetivas. A partir daí, a função será apresentar propostas, fiscalizar ações, despesas, cobrar providências, enfim, exercer o Controle Social do SASISUS em sua comunidade ou Distrito.

Essas situações geram interesses e necessidades diferenciadas, sendo indispensável respeitar essa forma original de ser, seus valores e tradições nos mínimos detalhes, inclusive na comunicação, fator essencial para que haja educação, que deve ser fácil e fluente.

Atualmente, cabe ao Ministério da Saúde, por meio da Secretaria Especial de Saúde Indígena (SESAI), criada pelo Decreto $\mathrm{n}^{\circ}$ 7.336, de 20 de outubro de 2010, a responsabilidade pela gestão dos DSEI, como consequência de reivindicação estrutural antiga, proposta pelos povos indígenas, também a capacitação dos Conselheiros de Saúde Indígena. A SESAI assume, assim, a responsabilidade pela capacitação dos sujeitos, através de práticas inovadoras e emancipadoras, para que o empoderamento não seja conflitante com os costumes e convicções trazidas de sua origem e do seu modo de sobrevivência.

Assim, são realizadas frequentes capacitações que contribuem para o avanço da política de saúde nos Distritos Sanitários Especiais de Saúde Indígena, por meio de uma 
efetiva participação dos conselheiros de saúde. Os temas discutidos durante esses momentos contemplaram conteúdos que estão presentes nas diretrizes da Política Nacional de Educação Permanente para o Controle Social no SUS, mas que foram adaptados para o Subsistema, estes conteúdos adaptados foram aprovados pelo Fórum de Presidentes de CONDISI, e que aborda os mais variados temas, como Política Nacional de Saúde Indígena, Planejamento e Financiamento do SUS e SASISUS, Intersetorialidade, Legislação sobre Controle Social, Participação Social e Informação e Comunicação em Saúde.

É importante salientar que o perfil educacional dos conselheiros que compõem o controle social da Saúde Indígena e no panorama atual nota-se uma larga diversidade, o que configura um grande desafio no processo de formação.

Gráfico 4. Escolaridade dos conselheiros por segmento representativo do Controle Social na Saúde Indígena.

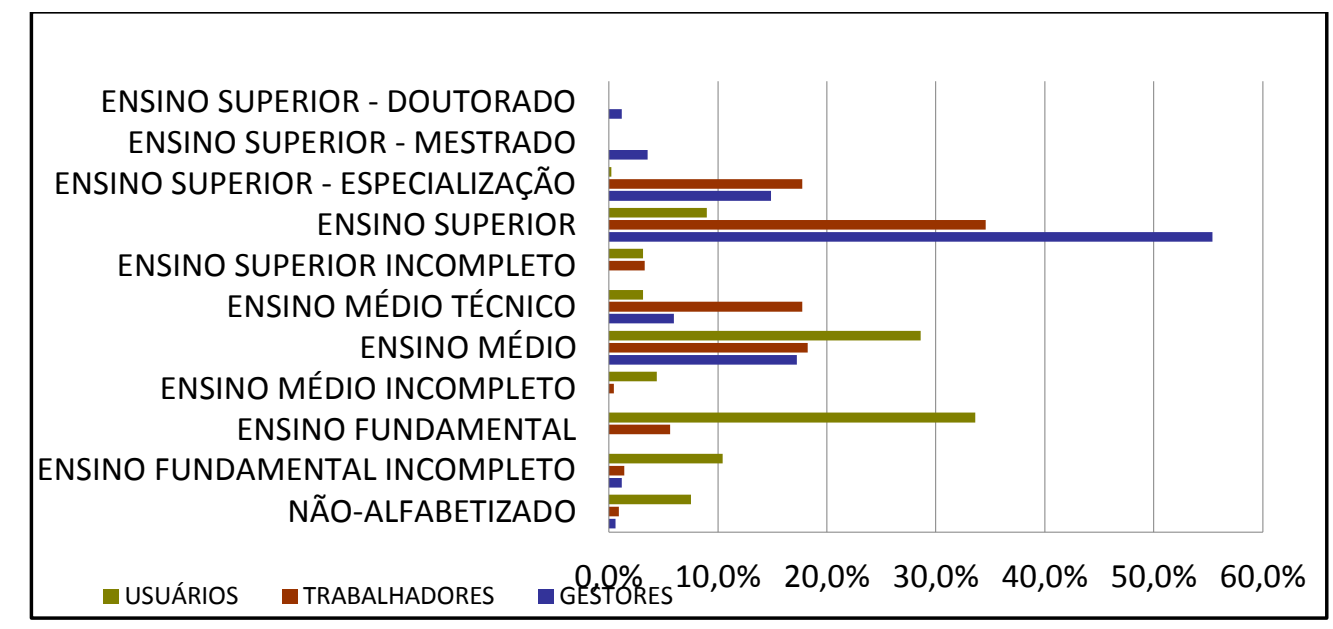

Fonte: SESAI/MS,2015.

Por fim, reforça-se a importância do Controle Social como ferramenta fundamental da construção de uma gestão democrática, representativa e universal. Entendendo assim que o empoderamento dos Conselheiros de Saúde Indígena é uma ação essencial no fortalecimento desse controle social e, ainda, a emancipação do individuo e de seus pares através da ascensão dele como promotor do conhecimento.

\section{Financiamento}


No Controle Social da Saúde Indígena, diferente da percepção de Stotz (2006) a respeito da fiscalização exercida pelos conselhos, que é de priorização do funcionamento dos serviços, deixando fora da pauta de discussões temas como a mudança do modelo assistencial e a capacitação de conselheiros, as representações da saúde indígenas, CLSI, CONDISI e FPCONDISI.

Os dados analisados apontam um crescente investimento nas ações do controle social após a criação da Secretaria Especial de Saúde Indígena do Ministério da Saúde, que além de estruturar de forma representativa a organização dos conselhos, avançou, também, no fortalecimento da estrutura de controle representada pelos CLSI, CONDISI e FPCONDISI.

Tabela 4. Investimento da SESAI no Controle Social da Saúde Indígena nos últimos cinco anos.

\begin{tabular}{|c|c|c|c|c|}
\hline 2011 & 2012 & 2013 & 2014 & $2015^{*}$ \\
\hline $2.114 .475,10$ & $2.330 .530,49$ & $2.423 .407,75$ & $3.151 .428,29$ & $4.154 .186,24$ \\
\hline
\end{tabular}

Fonte: SESAI/MS,2015.

Ferreira (2012) aponta que a ausência de um investimento sólido dentro do controle social da saúde indígena impossibilitava em muito as ações de capacitação dentre outras ações para o fortalecimento da participação social e, logo, do desenvolvimento da saúde indígena.

Destaca-se que no ano de 2011, iniciou-se a implantação do Programa de Inclusão Digital nos CONDISI, ressaltando que todos os 34 conselhos possuem espaço físico para realizar as atividades de controle social.

Tabela 5. Instrumentalização do Controle Social da Saúde Indígena no ano de 2011.

\begin{tabular}{|c|c|c|}
\hline Televisor & Computador & Impressora \\
\hline 48 & 60 & 34 \\
\hline
\end{tabular}

Fonte: SESAI/MS,2015. 
No que consta nos autos dos relatórios de demanda das representações sociais, a falta de condições materiais impedia em um dado momento anterior à criação da SESAI o exercício do controle social nos distritos, onde são executadas as ações de saúde e, portanto, onde é possível adequar os serviços de modo a considerar as características sociais e culturais dos povos que ali residem, partindo da necessidade identificada e manifestada pelos próprios usuários dos serviços de saúde, o que através da criação de um espaço físico pode fortalecer a institucionalização do controle social, conferindo permanência dentro da organização administrativa da gestão da saúde indígena.

A criação dos Conselhos Distritais de Saúde Indígena, de acordo Ferreira (2012), proporcionou o surgimento de um novo canal de comunicação entre a população indígena e o Estado brasileiro, implicando as diversas formas de organização e representação da população indígena no Brasil, evitando assim que as demandas desses povos fossem encaminhadas por organizações indígenas ou as próprias lideranças tradicionais que, muitas vezes, não tinham referenciamento e suas demandas frustradas.

\section{CONSIDERAÇÕES FINAIS}

O presente estudo evidencia um grande salto dado pelo controle social da saúde indígena após a criação da Secretaria Especial de Saúde Indígena. O fortalecimento dos Conselhos Distritais de Saúde Indígena proporciona o reforço da participação e representação social após a nova organização dada ao controle social, seja através da valorização dos conselheiros através do fortalecimento dos processos decisórios ou, ainda, através dos mecanismos de capacitação, possível graças ao homogêneo crescimento no investimento. Mas há de se reconhecer que ainda há possibilidades de avanços, com isso, um empoderamento maior por parte das comunidades indígenas na busca ao direito a uma saúde plena.

O fortalecimento do controle social na saúde indígena confere aos atores envolvidos nesse processo mais vozes através da representação democrática e, ainda, nas formas de consulta e controle da comunidade desde os processos decisórios, como na organização do controle de acordo a especificidade local até nas formas de avaliação dos profissionais e dos serviços desenvolvidos por eles. 
Assim, insta concluir que, embora seja uma história recente, marcado por construções junto às lideranças e movimentos indígenas, o Controle Social da Saúde Indígena desempenha um forte papel no compromisso de democratização do país. A organização do controle social apontada neste estudo demonstra uma larga representatividade étnica e abrangente, sendo suas instâncias com espaços bem delimitados por linhas de respeito e complementariedade, desde o Conselho Local de Saúde Indígena, Conselho Distrital de Saúde Indígena e, ainda, o Fórum de Presidente doe CONDISI.

A caracterização dos conselheiros torna-se fundamental para um melhor planejamento desde as ações de formação até as ações voltadas a gestão e planejamento das ações de saúde.

O presente estudo reforça a forte necessidade de qualificação e capacitação dos representantes das instancias de controle social na saúde indígena, como também a institucionalização através do fortalecimento e reconhecimento delas como parte integrante da gestão, através do envolvimento nas decisões e avaliação nas ações e processos.

Por fim, ressalta-se a necessidade da continuidade dos investimentos no Controle Social da Saúde Indígena, uma vez que o seu fortalecimento é, de fato, o fortalecimento do SASISUS e, consequentemente, do próprio Sistema Único de Saúde.

\section{REFERÊNCIAS}

BRASIL. Dispõe sobre as condições para a promoção, proteção e recuperação da saúde, a organização e o funcionamento dos serviços correspondentes e dá outras providências, instituindo o Subsistema de Atenção à Saúde Indígena. Lei № 9836, de 23 de setembro de 1999.

Constituição da República Federativa do Brasil de 1988. Brasília: Senado Federal. Subsecretaria de Edições Técnicas, 2000.

Fundação Nacional de Saúde. Política Nacional de Atenção dos Povos Indígenas. $2^{a}$ edição, Brasília - DF: Ministério da Saúde. Fundação Nacional de Saúde, 2002. 
Fundação Nacional de Saúde. Lei Arouca: a Funasa nos 10 anos de saúde indígena. Brasília: Funasa, 2009. 112p. Disponível em: http://www.funasa.gov.br/internet/Bibli_saudeInd.asp.

Dispõe sobre a organização do controle social no Subsistema de Atenção à Saúde Indígena. Ministério da Saúde. Portaria Ministerial № 755, de 18 de abril de 2012.

CORREIA, Maria. Valéria Costa. Que controle social? Os conselhos de saúde como instrumento. Rio de janeiro: Fiocruz. 2000.

RODRIGUES, Douglas. Artigo: controle social na saúde indígena: pontos para reflexão. Brasil, 2012.

SPOSATI,A \& LOBO,E. Cad.Saúde.Publ.Rio de Janeiro, 8(4):366-378, out/dez,1992.

CARVALHO, Antônio Ivo de. Conselhos de saúde no Brasil: participação cidadã e controle social. Rio de Janeiro, IBAM/IBASE. 1995.

FERREIRA, Luciana Benevides. O controle social no subsistema de atenção à saúde indígena: uma reflexão bioética. 2012. 147 f., il. Tese (Doutorado em Bioética)— Universidade de Brasília, Brasília, 2012.

GADOTTI, Moacir. Gestão Democrática da Educação com Participação Popular no Planejamento e na Organização da Educação Nacional. Disponível em http://Conae2014.mec.gov.br/images/pdf/artigo_moacir_gadotti.pdf

NOVO, Marina Pereira. Política e intermedicalidade no Alto Xingu: do modelo à prática de atenção à saúde indígena. Cad. Saúde Pública. 2011, vol.27, n.7, p. 13621370. Disponível em: < http://dx.doi.org/10.1590/S0102-311X2011000700011〉. 


\section{CONSIDERAÇÕES FINAIS DA DISSERTAÇÃO}

O processo de criação da Secretaria Especial de Saúde Indígena, fruto da mobilização dos movimentos indígenas, já representou uma forte atuação do controle social da saúde indígena, sendo a secretaria responsável pelo seu fortalecimento mediante ações regulamentadoras das instancias de controle.

As conferencias nacionais de saúde são fortes instrumentos do controle social da saúde indígena, principalmente pelo empoderamento e fortalecimento dos conselheiros e conselheiras que compões os Conselhos Locais, Distritais de Saúde Indígena e do Fórum de Presidentes de CONDISI, conhecedores de sua história e da necessidade de seu povo.

Embora seja uma história recente, marcado por construções junto às lideranças e movimentos indígenas, o Controle Social da Saúde Indígena desempenha um forte papel no compromisso de democratização do país. A organização do controle social apontada neste estudo demonstra uma larga representatividade étnica e abrangente, sendo suas instâncias com espaços bem delimitados por linhas de respeito e complementariedade, desde o Conselho Local de Saúde Indígena, Conselho Distrital de Saúde Indígena e, ainda, o Fórum de Presidente doe CONDISI.

Contudo, o presente trabalho reconhece as linhas de fragilidade do atual controle social da saúde indígena, porém constata estatisticamente os avanços através da reorganização, possível após a criação da Secretaria Especial de Saúde Indígena do Ministério da Saúde, mérito dos povos indígenas do Brasil. 


\section{REFERÊNCIAS}

ATHIAS, R.; MACHADO, M. A saúde indígena no processo de implantação dos Distritos Sanitários: temas críticos e propostas para um diálogo interdisciplinar. Cadernos de Saúde Pública, Rio de Janeiro, 17(2); 425-431, mar-abr, 2001.

BRASIL. Dispõe sobre as condições para a promoção, proteção e recuperação da saúde, a organização e o funcionamento dos serviços correspondentes e dá outras providências, instituindo o Subsistema de Atenção à Saúde Indígena. Lei № 9836, de 23 de setembro de 1999.

Constituição da República Federativa do Brasil de 1988. Brasília: Senado Federal, Subsecretaria de Edições Técnicas, 2000.

Fundação Nacional de Saúde. Política Nacional de Atenção dos Povos Indígenas. $2^{\text {a }}$ edição, Brasília - DF: Ministério da Saúde. Fundação Nacional de Saúde, 2002.

Fundação Nacional de Saúde. Lei Arouca: a Funasa nos 10 anos de saúde

indígena. Brasília: Funasa, 2009. 112p. Disponível em: http://www.funasa.gov.br/internet/Bibli_saudeInd.asp

Coletânea de normas para o controle social no Sistema Único de Saúde. Brasília: Ministério da Saúde, 2011.

Dispõe sobre a organização do controle social no Subsistema de Atenção à Saúde Indígena. Ministério da Saúde. Portaria Ministerial $N^{\circ} 755$, de 18 de abril de 2012.

Para entender o controle social na saúde / Ministério da Saúde, Conselho Nacional de Saúde. - Brasília : Ministério da Saúde, 2013.

Resolução $n^{\circ}$ 461/12. Acessado em novembro de 2014. Disponível em: conselho.saude.gov.br/resolucoes/2012/Reso461.doc. 
- Ministério da Saúde. Acessado em novembro de 2014. Disponível em: http://portalsaude.saude.gov.br/index.php/o-ministerio/principal/secretarias/secretariasesai/mais-sobre-sesai/9540-destaques. 2014b.

Ministério da Saúde. $5^{\text {a }}$ Conferência Nacional de Saúde Indígena : relatório final / Ministério da Saúde, Conselho Nacional de Saúde. - Brasília: Ministério da Saúde, 2015.

CARVALHO, Antônio Ivo de. Conselhos de saúde no Brasil: participação cidadã e controle social. Rio de Janeiro, IBAM/IBASE. 1995.

CORREIA, Maria. Valéria Costa. Que controle social? Os conselhos de saúde como instrumento. Rio de janeiro: Fiocruz. 2000.

FERREIRA, Luciana Benevides. O controle social no subsistema de atenção à saúde indígena: uma reflexão bioética. 2012. 147 f., il. Tese (Doutorado em Bioética)— Universidade de Brasília, Brasília, 2012.

GARNELO, M. L.; SAMPAIO, S. Organizações indígenas e distritalização sanitária: os riscos de "fazer ver" e "fazer crer" nas políticas de saúde. Cad. Saúde Pública, Rio de Janeiro, 21(4):1217-1223, jul-ago, 2005.

GARNELO, Luiza(Org.). Saúde Indígena: uma introdução ao tema. / Luiza Garnelo; Ana Lúcia Pontes (Org.). - Brasília: MEC-SECADI, 2012.

MARTINS, A. L. Política de saúde indígena no Brasil: reflexões sobre o processo de implementação do Subsistema de Atenção à Saúde Indígena. / André Luiz Martins. 2013 ( dissertação). 
PRODANOV, C. C; FREITAS, E.C.. Metodologia do trabalho científico [recurso eletrônico] : métodos e técnicas da pesquisa e do trabalho acadêmico. 2a. ed. Novo Hamburgo: Feevale, 2013.

RAUEN, Fábio José. Elementos de iniciação à pesquisa. Rio Grande do Sul: nova Era, 1999.

RODRIGUES, Douglas. Artigo: controle social na saúde indígena: pontos para reflexão. Brasil, 2012.

SPOSATI,A\& LOBO,E. Cad.Saúde.Publ.Rio de Janeiro, 8(4):366-378, out/dez, 1992.

TEIXEIRA, C. C.; AGUILAR, N. . Controle Social na Saúde Indígena: limites e possibilidades da democracia direta. Tempus: Actas de Saúde Coletiva, v. 7, p. 97-115, 2013

GADOTTI, Moacir. Gestão Democrática da Educação com Participação Popular no Planejamento e na Organização da Educação Nacional. Disponível em http://Conae2014.mec.gov.br/images/pdf/artigo_moacir_gadotti.pdf

NOVO, Marina Pereira. Política e intermedicalidade no Alto Xingu: do modelo à prática de atenção à saúde indígena. Cad. Saúde Pública. 2011, vol.27, n.7, p. 13621370. Disponível em: < http://dx.doi.org/10.1590/S0102-311X2011000700011>

ROCHA, Enid. A Constituição cidadã e a institucionalização dos espaços de participação social: avanços e desafios. 20 anos da constituição cidadã: avaliação e desafio da seguridade social, Anfip, Brasília, 2008.

SOUZA, Antônio. A. et.al. Instituto Nacional de Saúde Indígena: institucionalidade necessária. Tempus, actas de saúde colet, Brasília, 9(2), 149-163, jun, 2015. 
ANEXO1- REPRESENTAÇÃO DE ETNIAS POR SEGMENTO.

\begin{tabular}{|l|l|l|}
\hline USUÁRIO & GESTOR & TRABALHADOR \\
\hline AMANAYÉ & BARÉ & ATIKUM \\
\hline AMONDAWA & KAMBEBA & BARÉ \\
\hline ANACẼ & KOKAMA & DESSANO \\
\hline ANAMBÉ & MACUXI & GUAJAJARA \\
\hline APIAKA & MARAGUA & GUARANI \\
\hline APURINÃ & MARUBO & KA \\
\hline ARAPASO & MUNDURUKU & KAINGANG \\
\hline ASHANINKA & NUKINI & KAYAPÓ \\
\hline ASSURINI & PANKARARÚ & KRIKATI \\
\hline ATIKUM & POTIGUARA & MANOKI \\
\hline ATIKUM CISA & SATERÉ-MAWÉ & MARUBO \\
\hline AWÁ-GUAJÁ & TICUNA & MAYORUNA \\
\hline BAKAIRI & TUCANO & MIRITITAPUIA \\
\hline BANIWA & WAPIXANA & MUNDURUKU \\
\hline BARÉ & YANOMAMI & MURA \\
\hline BORORO & YEKUANA & MURA \\
\hline CASSUPÁ́ & & NUKINI \\
\hline CHIQUITANO & & ORO MON \\
\hline CINTA LARGA & & ORO WARAN XIJEIN \\
\hline CURIPACO & & PAINTINTIN \\
\hline DESSANO & & PANKARÁ \\
\hline DIARROI & & PANKARARÚ \\
\hline FULNI-Ố & & PANKARARÚ \\
\hline GAVIÃO & & PARSI \\
\hline GUAJAJARA & & PIPIPÃ \\
\hline GUARANI & & PIRATAPUIA \\
\hline GUATÓ & & POTIGUARA \\
\hline HEXKARYANA & & PWYANAWA \\
\hline HISCARIANO & & SATERÉ-MAWÉ \\
\hline JAMAMADI & & TAPEBA \\
\hline JAMINAWA & & TEMBÉ \\
\hline JENIPAPO KANINDÉ & & TICUNA \\
\hline JURUNA & & TUPARI \\
\hline KA & & TUPARI \\
\hline KAAPOR & & XAVANTE \\
\hline KAIAPO & & XUKURU DE CIMBRES \\
\hline KAIGANG & & YANOMAMI ORORUBÁ \\
\hline KAIXANA & & YEKUANA \\
\hline KAMBEBÁ & & \\
\hline KAMBIWÁ & & \\
\hline KAMBIWÁ - TUXÁ & & \\
\hline KAMPÉ & & \\
\hline KANAMARI & & \\
\hline
\end{tabular}




\begin{tabular}{|l|l|l|}
\hline KANELA APANIEKRÁ & & \\
\hline KANELA & & \\
\hline RANKOKAMEKRÁ & & \\
\hline KANINDÉ & & \\
\hline KAPINAWÁ & & \\
\hline KARIPUNA & & \\
\hline KAXARARI & & \\
\hline KAXINAWA & & \\
\hline KAYAPÓ & & \\
\hline KOKAMA & & \\
\hline KRENAK & & \\
\hline KRENIẾ & & \\
\hline KRIKATI & & \\
\hline KULINA & & \\
\hline KURÂ BAKAIRI & & \\
\hline MAKU & & \\
\hline MANCHINERY & & \\
\hline MANOKI & & \\
\hline MARUAGUA & & \\
\hline MARUBO & & \\
\hline MATIS & & \\
\hline MAXAKALI & & \\
\hline MAYURUNA & & \\
\hline MIRANHA & & \\
\hline MOKURIÑ & & \\
\hline MUNDURUKU & & \\
\hline MURA & & \\
\hline MYKY & & \\
\hline NAMBIKWARA & & \\
\hline NUKINI & & \\
\hline ORO MON & & \\
\hline ORO WARAN & & \\
\hline ORO WARAN XIJEIN & & \\
\hline ORO WIN/CABIXI & & \\
\hline PANARÁ & & \\
\hline PANKARÁ & & \\
\hline PANKARARÚ & & \\
\hline PANKARARU ENTRE & & \\
\hline SERRAS & & \\
\hline PARESI & & \\
\hline PATAXÓ & & \\
\hline PIPIPÃ & & \\
\hline PIRATAPUIA & & \\
\hline PITAGUARY & & \\
\hline POTIGUARA & & \\
\hline
\end{tabular}




\begin{tabular}{|l|l|l|}
\hline PURUBORA & & \\
\hline RIKBAKTSA & & \\
\hline SANUMA & & \\
\hline SATERÉ-MAWÉ & & \\
\hline SHANENAWA & & \\
\hline SHAWANENAWA & & \\
\hline TABAJARA & & \\
\hline TAPAYUNA & & \\
\hline TAPEBA & & \\
\hline TARIANO & & \\
\hline TEMBÉ & & \\
\hline TENHARIN & & \\
\hline TERENA & & \\
\hline TICUNA & & \\
\hline TIMBIRA & & \\
\hline TREMEMBÉ & & \\
\hline TRUKÁ & & \\
\hline TRUMAI & & \\
\hline TUCANO & & \\
\hline TUIUKA & & \\
\hline TUPARI & & \\
\hline TUPINIQUIM & & \\
\hline TUYUCA & & \\
\hline UANANO & & \\
\hline UMUTINA & & \\
\hline URU EU WAU WAU & & \\
\hline WAI WAI & & \\
\hline WEREKENA & & \\
\hline WITOTA & & \\
\hline XAKRIABÁ & & \\
\hline XAVANTE & & \\
\hline XIKRIN & & \\
\hline XIRIXANA & & \\
\hline XUKURU DE CIMBRES & & \\
\hline XUKURU DE ORORUBÁ & & \\
\hline YANOMAMI & & \\
\hline YEKUANA & & \\
\hline ZORÓ & & \\
\hline
\end{tabular}

